Minireview

\title{
Engine of life and big bang of evolution: a personal perspective
}

\author{
James Barber \\ Wolfson Laboratories, Department of Biological Sciences, South Kensington Campus, Imperial College London, \\ SW7 2AZ, UK (e-mail: j.barber@imperial.ac.uk; fax: +44-20-75945267)
}

Received 29 April 2003; accepted in revised form 19 November 2003

Key words: cation effects, chlorophyll fluorescence, delayed light (delayed-light emission), history, Photosystem II, structure

\begin{abstract}
Photosystem II (PS II) is the engine for essentially all life on our planet and its beginning 2.5 billion years ago was the 'big bang of evolution.' It produces reducing equivalents for making organic compounds on an enormous scale and at the same time provides us with an oxygenic atmosphere and protection against UV radiation (in the form of the ozone layer). In 1967, when I began my career in photosynthesis research, little was known about PS II. The Zscheme had been formulated [Hill and Bendall (1960) Nature 186: 136-137] and Boardman and Anderson [(1964) Nature 203: 166-167] had isolated PS II as a discrete biochemical entity. PS II was known not only to be the source of oxygen but of variable chlorophyll fluorescence [Duysens and Sweers (1963) In: Studies on Microalgae and Photosynthetic Bacteria, pp. 353-372. University of Tokyo Press, Tokyo] and delayed chlorophyll fluorescence [Arnold and Davidson (1954) J Gen Physiol 37: 677-684]. P680 had just been discovered [Döring et al. (1967) Z Naturforsch 22b: 639-644]. No wonder the 'black box of PS II' was described at that time by Bessel Kok and George Cheniae [Current Topics in Bioenergetics 1: 1-47 (1966)] as the 'inner sanctum of photosynthesis.' What a change in our level of understanding of PS II since then! The contributions of many talented scientists have unraveled the mechanisms and structural basis of PS II function and we are now very close to revealing the molecular details of the remarkable and thermodynamically demanding reaction which it catalyzes, namely the splitting of water into its elemental constituents. It has been a privilege to be involved in this journey.
\end{abstract}

Abbreviations: A23187 - antibiotic ionophore which facilitates $\mathrm{Mg}^{2+} / \mathrm{H}^{+}$exchange across membranes; Chl chlorophyll; DCMU - 3-(3,4-dichlorophenyl)-1,1-dimethylurea; EM - electron microscopy; EPR - electron paramagnetic resonance; LHCII - light-harvesting complex of PS II; NPQ - nonphotochemical quenching (of chlorophyll fluorescence); PS I - Photosystem I; PS II - Photosystem II

\section{Getting to know my way around Photosystem II (PS II)}

\section{Delayed chlorophyll fluorescence}

In 1967, I went to work in Lou Duysens' laboratory in the University of Leiden (The Netherlands) as a postdoc. I knew little or nothing about photosynthesis but something about membrane physiology and biophysics. It was not surprising therefore that I found myself collaborating with Bert Kraan on a project which was prompted by an intriguing observation of Berger Mayne and Rod Clayton (1966). They had shown that by subjecting chloroplast thylakoids to an acidbase shift, similar to that used by André Jagendorf and E. Uribe (1966) to induce ATP synthesis in the dark, brought about acceleration in the emission of delayed chlorophyll ( $\mathrm{Chl}$ ) fluorescence (also called delayed light emission) from PS II. This acidbase induced luminescence was clearly a membranecontrolled phenomenon and it therefore seemed to me that a similar stimulation of delayed fluorescence should occur if an electrical gradient of correct polarity was induced rather than a $\mathrm{pH}$ gradient. This thinking, of course, was triggered not only by my $\mathrm{PhD}$ training in membrane biophysics, under the 
supervision of Professor Jack Dainty, but also by the concepts Peter Mitchell was vigorously advocating at that time (Mitchell 1966). My idea was to induce the membrane potential by creating a salt gradient across the chloroplast thylakoid membrane. At about the same time a similar approach was used by Baz Jackson and Tony Crofts (1969) to induce carotenoid band shifts in the bacterial chromatophore membrane. Given that the thylakoid membrane would be expected to show differential ionic permeabilities, then a diffusion potential would be created. Indeed the first experiments using $\mathrm{KCl}$ pulses resulted in the anticipated stimulation of delayed light emission. The size of the salt induced signal increased if valinomycin was present or when the potassium salt consisted of a large, poorly diffusible anion, such as benzoate. Clearly it was the generation of membrane potential with inside (lumen) positive that lowered the activation energy for delayed light emission; $L \alpha \exp (E-\Delta \Psi)$ where $E$ is the activation energy necessary to lift the electron from a metastable state to the Chl singlet, $\Delta \Psi$ is the membrane potential and $L$ is the intensity of the delayed light. The results obtained in Leiden were published (Barber and Kraan 1970) and after joining the faculty at Imperial College in 1968, I continued to exploit the phenomenon. I began by estimating the size of the light-induced membrane potential generated across the thylakoid membrane of higher-plant chloroplasts and to calculate the relative and absolute permeabilities of a number of ionic species used to create the diffusion potential (Barber 1972a, b). Perhaps more importantly, my analysis of salt-induced luminescence implied that the species involved in the back reactions giving rise to the emission of light were positioned on opposite sides of the membrane and therefore vectorial movement of charge occurred in line with Mitchell's principles. This view was shared with Colin Wraight and Antony (Tony) Crofts (1971) who also recognized that the intensity of millisecond delayed light reflected the size of the high energy state across the thylakoid membrane and vectorial nature of the recombination process. William (Bill) Arnold (Arnold and Azzi 1971) discovered 'electroluminescence'; Kenneth (Ken) Sauer (Ellenson and Sauer 1976) and Hans van Gorkom (de Grooth and van Gorkom 1981) studied the effects of electrical gradients on delayed light emission. However, the usefulness of delayed light emission as a tool to study the electron transfer and thermodynamics of PS II was brought to the forefront by Bill Rutherford, Govindjee and Yorinao Inoue (1984) who investigated, in parallel, different phases of delayed light emission and thermoluminescence. Although originally discovered by Arnold and Sherwood (1957), it was this pioneering work that was the basis for the correlation of different thermoluminescence bands with different recombination processes. From this analysis emerged a technique which has provided much information about charge storage in PS II, as reviewed in Imre Vass and Inoue (1992); see also the historical perspective by Vass (2003).

\section{Prompt chlorophyll fluorescence}

It had been shown by Arnold and colleagues (Strehler and Arnold 1951; Arnold and Davidson 1954) that delayed fluorescence had the same spectrum as Chl prompt fluorescence, therefore originating from the singlet state of Chl $a$. It was also known from the pioneering work of Louis N.M. (Lou) Duysens (Duysens and Sweers 1963) and others (reviewed by Govindjee and Papageorgiou 1971; for an historical account, see Govindjee 1995) that the majority of the prompt Chl fluorescence from higher plants and algae originated from PS II and that its yield varied with the redox state of the PS II reaction center (RC). When the $\mathrm{RC}$ was open the yield was low $\left(\mathrm{F}_{\mathrm{o}}\right)$, and rose to a maximum $\left(\mathrm{F}_{\mathrm{m}}\right)$ as the $\mathrm{RC}$ closed. As shown by Hans Kautsky (Kautsky et al. 1960); Jean Lavorel (1959); Govindjee (Munday and Govindjee 1969) and others, in the case of intact cells this fluorescence rise could be complex, reflecting the secondary electron transfer events into and out of the PS II RC, as elegantly analyzed by Shmuel Malkin and Bessel Kok (1966). Also the kinetics of the fluorescence rise from $\mathrm{F}_{\mathrm{o}}$ (the initial) to $F_{m}$ (maximal) included the possibility of energy transfer between adjacent PS II units as first studied by Pierre Joliot and Anne Joliot (1964), see also Joliot and Joliot (2003). Even after reaching the $\mathrm{F}_{\mathrm{m}}$ level, subsequent changes in fluorescence yield occurred due to other phenomena associated with membrane gradients ( $\Delta \mathrm{pH}$; Wraight and Crofts 1970) or state-transitions (Bonaventura and Myers 1969); see also Allen (2002). It was therefore important that my quantitative analyses of delayed fluorescence took into account changes in fluorescence yield (Hipkins and Barber 1974; Barber et al. 1977b). Because of this I became aware of the large changes in the $F_{m}$ level that could be induced with isolated thylakoid membranes by changing the salt levels of the suspension medium. In a medium of low ionic strength (typically $5 \mathrm{mM} \mathrm{NaCl}$ ) the $\mathrm{F}_{\mathrm{m}}$ level was relatively low but addition of, for example, $5 \mathrm{mM} \mathrm{MgCl}_{2}$ resulted 
in a large increase in fluorescence yield giving an $\mathrm{F}_{\mathrm{m}} / \mathrm{F}_{\mathrm{o}}$ ratio more typical of that observed in vivo. The $\mathrm{Mg}^{2+}$-induced increase in the $\mathrm{F}_{\mathrm{m}}$ level had been observed and studied initially by Peter Homann (1969) and Norio Murata (1969) and later by others (e.g., Mohanty et al. 1973).

It was therefore a natural extension of my studies of delayed luminescence to explore this $\mathrm{Mg}^{2+}$ induced phenomenon. Together with Alison Telfer, John Mills and Jenny Nicolson, we found that the 'high in vivo $\mathrm{F}_{\mathrm{m}}$ ' level was maintained in isolated intact chloroplasts even when suspended in low salt medium (Barber et al. 1974b; Mills and Barber 1975). Only when the isolated intact chloroplasts were osmotically shocked did the $\mathrm{F}_{\mathrm{m}}$ drop to the 'low salt' level. Addition of $5 \mathrm{mM} \mathrm{MgCl} 2$ restored the $\mathrm{F}_{\mathrm{m}}$ level to that observed with the intact chloroplasts. Moreover, when the intact chloroplasts were illuminated with actinic light, the $\mathrm{F}_{\mathrm{m}}$ level slowly declined with time, an effect reminiscent of that observed in intact leaves and algal cells as originally described by Kautsky et al. (1960). Addition of uncouplers restored the $F_{m}$ level to its original high value. We therefore interpreted most of this slow decrease in $\mathrm{F}_{\mathrm{m}}$ as being due to the build up of a $\Delta \mathrm{pH}$ across the thylakoid membrane. This phenomenon has subsequently been termed 'nonphotochemical quenching' or NPQ. My work in this area was paralleled by that of G. Heinrich Krause (1974) who later, with Claudie Vernotte and Jean-Marie Briantais, went on to publish a definitive paper which essentially established the relationship between $\mathrm{Chl} a$ fluorescence changes and proton gradient during the slow decay of fluorescence transient (Briantais et al. 1979; Krause et al. 1982).

At about that time I became aware of the work of Lester Packer (Murakami and Packer 1971) and others who showed that under low salt conditions isolated thylakoids become unstacked and that the addition of $5 \mathrm{mM} \mathrm{Mg}^{2+}$ induced stacking to form granal/stromal regions. We therefore concluded that within the intact chloroplasts there was sufficient $\mathrm{Mg}^{2+}$ to maintain thylakoid membrane stacking and the high $\mathrm{F}_{\mathrm{m}}$ level. We also concluded that it was likely that in the intact chloroplast, $\mathrm{Mg}^{2+}$ acted as the counterion for $\mathrm{H}^{+}$pumping as emphasized by the action of ionophore A23187 (Barber et al. 1974c). Much of my thinking on this subject was presented in Chapter 3 of 'The Intact Chloroplast' which was the first volume of a series entitled Topics in Photosynthesis (Barber 1976).

\section{First thoughts about PS II structure}

The apparent correlation between the $F_{m}$ level and conformational state of the thylakoids was reinforced by freeze-fracture studies which indicated that various particles attributed to Photosystem I (PS I), PS II, light harvesting and the ATP synthase $\mathrm{CF}_{0}-\mathrm{CF}_{1}$ complexes, were randomized under low salt conditions but partitioned into stacked and unstacked regions of the membrane on the addition of $5 \mathrm{mM} \mathrm{MgCl}_{2}$ (Ojakian and Satir 1974; Staehelin 1976). Moreover these changes could also be induced by other divalent cations and by higher levels of monovalent cations such as $\mathrm{Na}^{+}$and $\mathrm{K}^{+}$. Using Chl fluorescence I decided, with the help of John Mills, Andrew Love, Geoff Searle, Fred Chow, Herb Nakatani and Barry Rubin, to make a thorough analysis of these cationinduced effects and concluded that they controlled the structure of the thylakoid membrane by electrostatically screening surface electrical charges (Barber et al. 1977a; Barber and Searle 1978, 1979; Barber and Chow 1979; Chow and Barber 1980; Nakatani and Barber 1980; Rubin and Barber 1980) and thus changing the balance between coulombic repulsive forces and electrodynamic attractive forces (e.g., long-range van der Waals) (Barber 1980b, 1982).

It was the in-depth analyses and associated experiments which led me to suggest that the two photosystems were laterally separated, with PS II located in the granal regions and PS I in the stromal lamellae (Barber 1980a, b; see discussions in Barber 1979 and associated recorded discussions; also see Anderson and Andersson 1981 and Barber et al. 1981); a similar idea had emerged earlier from the PhD thesis of Bertil Andersson (1978). Bertil Andersson together with Jan Anderson, obtained biochemical evidence to support the concept (1980). For further historical perspectives on this topic, see Anderson (2002) and Albertsson (2003). Thus lowering of the $F_{m}$ fluorescence level when thylakoid membranes were unstacked could be understood in terms of the intermixing of the two photosystems, resulting in an increase in excitation energy transfer from PS II to PS I. The idea of lateral heterogeneity was, however, not totally new at that time. Roderick (Rod) Park and P.V. (Raj) Sane (1971) and Staehelin et al. (1976) have reviewed the early literature. Further, based on the studies of separation of PS I and PS II by nondetergent methods (Sane et al. 1970), Park and Sane (1971) proposed a model in which PS I was located in the stroma lamellae, granal margins and end membranes, whereas both PS I and PS II were 
located in appressed membranes in grana (partitions). It was the dogma at that time that PS I and PS II were stoichiometrically related in the grana and in this way were responsible for noncyclic electron flow. Such a relationship was, for example, the basis of Warren Butler's 'tripartite model' where he proposed that the two photosystems were excitonically coupled. At the Ciba Meeting in London (1979) those present did not challenge this concept and therefore my ideas presented at this meeting seemed to go nowhere. However the idea of the 'extreme' lateral separation of pigment systems is now well accepted: PS II is only in the appressed grana region, but PS I is in the stroma lamellae, the end membranes and margins of grana (for one of the current models, see Albertsson 2001). For an historical account of the chloroplast structure, see Staehelin (2003).

The concept of lateral separation of PS II and PS I in higher plant chloroplasts is the basis for biochemical and structural studies of PS II heralded by the work of Berthold, Babcock and Yocum (1981) who described a simple procedure to isolate a PS II-enriched stacked membrane fraction using Triton $\mathrm{X}-100$ (known as BBYs).

\section{The era of PS II biochemistry}

The BBY preparation has had enormous implications both for biochemical and biophysical measurements. It provided, for example, the starting point for isolating the PS II RC consisting of the D1 and D2 proteins and the $\alpha$ - and $\beta$-subunits of cytochrome $b 559$ by Nanba and Satoh (1987); see also Satoh (2003). My colleagues and I were able to reproduce their method (Barber et al. 1987; Marder et al. 1987) and later modified it so as to increase the stability of the isolated complex (Chapman et al. 1988). At about the same time, Seibert et al. (1988) described the substitution of lauryl maltoside for Triton to improve the stability of the RC. Further, McTavish et al. (1989) and Crystal et al. (1989) provided methods to scrub oxygen out of the system to stabilize the RCs for accurate experimental use in the presence of light. The low Chl level bound to this stabilized preparation, which we determined to be 6 Chls per 2 pheophytin (Gounaris et al. 1990), at last provided an experimental system for investigating the kinetics of primary charge separation in PS II using femto- and pico-second spectroscopy. In this respect I had a very productive collaboration with Professor Lord Porter and colleagues and
PhD students, especially David Klug, Paula Booth, Linda Giorgi, Gary Hastings, Steve Merry and James Durrant (summarized in Klug et al. 1998). At about the same time, experiments at the Argonne National laboratory, using RC preparations, prepared by Seibert and coworkers, were conducted by Mike Wasielewski, Govindjee and Mike Seibert and their coworkers (Wasielewski et al. 1989; summarized in Seibert and Wasielewski 2003). The overlap in the absorption of the chlorins within the PS II RC gave rise to the delocalization of excited states and contrasted with the primary photochemistry of bacterial RCs (Durrant et al. 1995). The work also showed that the P680 triplet state was long lived $(1 \mathrm{~ms})$ under anaerobic conditions with no quenching by the $\beta$-carotene molecules present in the RC (Durrant et al. 1990). When oxygen was present the lifetime of the P680 triplet shortened to $20 \mu \mathrm{s}$ and singlet oxygen was formed (Telfer et al. 1994). I believe that it is this inherent and unique property of PS II that gives rise to its vulnerability to photoinduced damage manifested by the rapid turnover of the D1 protein (see Barber 1994). In PS II it is not possible to place the $\beta$-carotene sufficiently close to the high-potential chlorophylls of P680 for triplet-triplet transfer and at the same time avoid their photo-oxidation. Therefore, the generation of highly reactive singlet oxygen is not prevented by rapid transfer of the chlorophyll triplet to a nearby carotenoid.

Although the isolated D1/D2/Cyt b559 complex proved to be a useful preparation that once and for all established the functional homologies between the D1 and D2 proteins and the L and M subunits of the bacterial RC, it also had many shortcomings. It did not retain true $\mathrm{Q}_{\mathrm{A}}$ and $\mathrm{Q}_{\mathrm{B}}$ activities, the nonheme iron was not present and the EPR signals due to the formation of $\mathrm{Tyr}_{\mathrm{Z}}$ and $\mathrm{Tyr}_{\mathrm{D}}$ radicals were not detected. Therefore it was unlikely that such a stripped down complex could carry out full PS II function; namely waterplastoquinone oxidoreductase activity. I therefore turned my attentions to larger, fully functional PS II complexes with the view to determine their structures.

\section{Structure of PS II}

\section{Monomer or dimer?}

With considerable input from my $\mathrm{PhD}$ student Ben Hankamer, we developed protocols to isolate oxygen evolving PS II complex from spinach. Ben found mild digestion procedures produced dimeric as well 
as monomeric core complexes with molecular mass of about 500 and $250 \mathrm{kDa}$, respectively (Hankamer et al. 1997b). At that time I was not convinced that the dimeric form was of physiological significance although others had suggested PS II was dimeric (Seibert et al. 1987; Bassi et al. 1989; Peter and Thornber 1991; Lyon et al. 1993; Seibert 1995). However, it was the work of Jon Nield, another PhD student, who together with Ben isolated a large dimeric supercomplex that contained in addition to the core PS II proteins, the light harvesting complex (LHCII), CP29 and CP26, which persuaded me that the dimeric state was physiologically relevant. The first structural information of our PS II core dimer and the LHCII-PS II supercomplex was obtained by electron microscopy (EM) through collaboration with Egbert Boekema and Mathias Rögner (Boekema et al. 1995). This work clearly showed how the core dimer was centrally placed within the supercomplex and in some

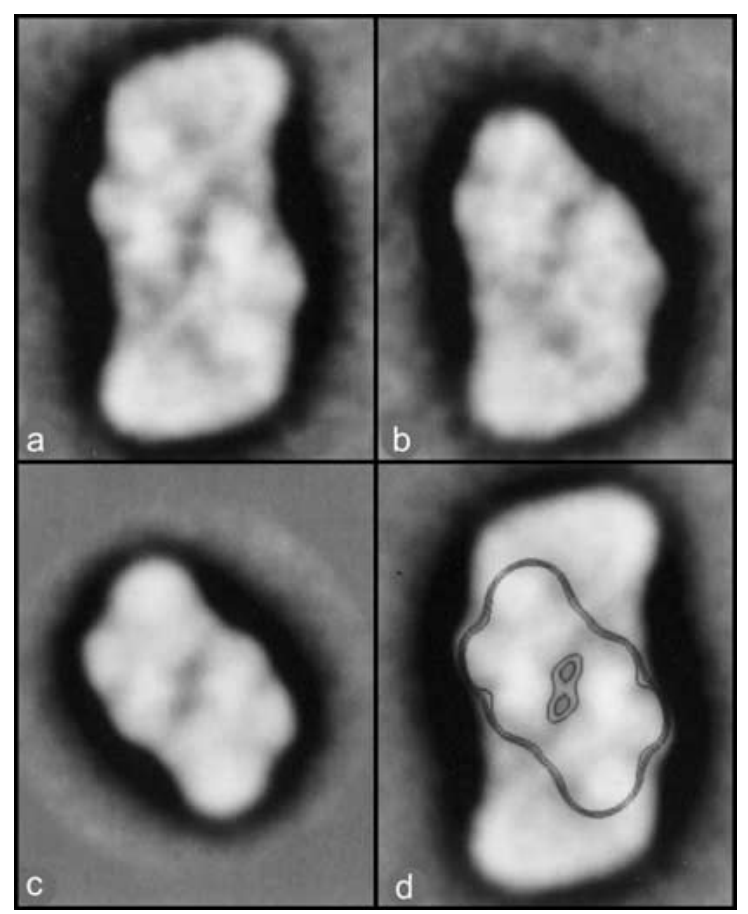

Figure 1. Averaged images of the top views of PS II particles isolated from spinach observed in the electron microscope after negative staining. (a) Complete LHCII-PS II supercomplex having dimensions of approximately $29 \times 12 \mathrm{~nm}$. (b) A top view of the LHCII-PS II supercomplex missing a set of Cab-proteins (LHCII, CP29 and CP26) on one side of the core dimer. (c) PS II core dimer having dimensions of approximately $17 \times 10 \mathrm{~nm}$. (d) Complete LHCII-PS II supercomplex with an outline of the core dimer. (Modified from Boekema et al. 1995.) cases we could see particles where the flanking LHCII, CP29 and CP26 proteins had been lost from one side (Figure 1). The idea that PS II was dimeric had been advocated and accepted for cyanobacteria without controversy. However, the earlier EM work of Andreas Holzenberg and Robert C. Ford (Holzenberg et al. 1993) on PS II structure of higher plants had been interpreted as monomeric. Thus for some time the monomer-dimer issue became controversial as discussed in our 1997 review (Hankamer et al. 1997a).

\section{CP47-RC complex}

The biochemical protocols established by Ben Hankamer and Jon Nield paved the way for our subsequent structural studies. In the absence of good 3-D crystals, I decided to exploit high resolution EM both through single particle analyses and electron crystallography. Our first success was to grow 2-D crystals of PS II subcore complexes containing the D1, D2 and CP47 proteins as well as low molecular weight proteins including the $\alpha$ - and $\beta$-subunits of cytochrome b559 (CP47-RC complex). At about the same time, Nakazato et al. (1996) also produced 2-D crystals of PS II. However, we did not have direct access to a high-voltage electron microscope with a lowtemperature stage required to obtain structures with good resolution. Thus, I collaborated with Werner Kühlbrandt at the European Molecular Biology Laboratory (EMBL) in Heidelberg (Germany). He had just taken on a new PhD student, Kyong-He Rhee from Korea, who would conduct the electron cryomicroscopy and subsequent image processing. At Imperial College, my colleague Ed Morris, could use our lowvoltage electron microscope to check the quality of the 2-D crystals. The collaboration worked well and in 1997 we obtained an $8 \AA$ projection map of PS II (Rhee et al. 1997). One year later the 3-D map was calculated and for the first time we were able to visualize directly the organization of the transmembrane helices in PS II (Rhee et al. 1998). Ten helices were readily identified as those of the D1 and D2 proteins since they were organized in a manner very similar to those of the $L$ and $M$ subunits. Six further transmembrane helices were assigned to CP47 which were arranged in a circular manner very much like the six N-terminal helices of the PS I RC proteins, PsaA and $\mathrm{PsaB}$ which had been determined by X-ray crystallography to $4 \AA$ by the Berlin group (Krauß et al. 1996). This structural similarity 
established that there is a common evolutionary origin for PS I and PS II RC (Rhee et al. 1998); the same idea was also proposed by Schubert et al. (1998) at about the same time. We assigned other densities to seven further transmembrane helices and to the porphyrin head groups of Chls and pheophytin molecules. According to these assignments CP47 bound $14 \mathrm{Chl}$ molecules and more importantly the chlorins bound within the D1 and D2 proteins were arranged some what like those in the bacterial RC. However, our work established that there was no real 'special pair' and that the four chlorophylls on the donor side were equally spaced based on center to center distances (Figure 2). This important conclusion was confirmed three years later by the X-ray studies of Zouni et al. (2001) (see Figure 2b) and again by Kamiya and Shen (2003). However, a comparison of Figures $2 \mathrm{a}$ and $\mathrm{b}$ does show some differences in the orientation of accessory chlorophylls. Our work, and that of the X-ray crystallographers, has opened up the debate as to 'where and what is P680?' (see Barber

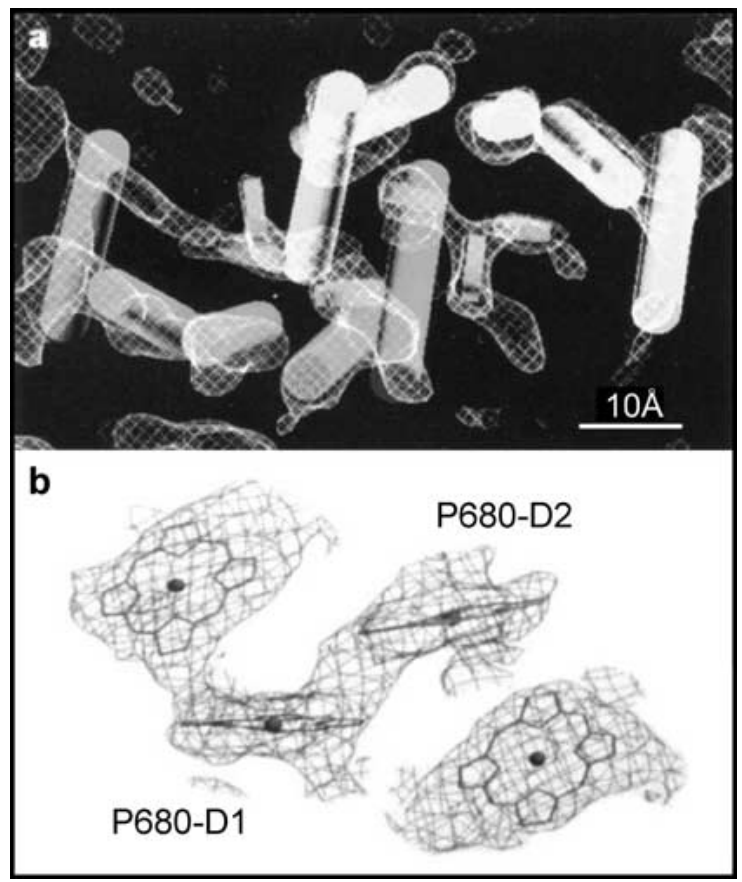

Figure 2. (a) Positioning of the four 'core' chlorophylls and two pheophytins within the D1 and D2 transmembrane helices showing the absence of a special pair in PS II. The data was obtained by electron crystallography and published in Rhee et al. (1998). (b) Positioning of the four 'core' chlorophylls of P680 as determined by X-ray crystallography confirming the absence of a special pair in PS II (Zouni et al. 2001) where P680-D1 is the Chl ligated to D1His198 and P680-D2 is the Chl ligated to D2His197.
2001). From recent work (Dekker and van Grondelle 2000; Prokhorenko and Holzwarth 2000; Diner et al. 2001) it seems likely that PS II contrasts with the purple bacterial RC in that primary charge separation originates from an 'accessory' chlorophyll in PS II and that 'hole' migration occurs as indicated in Figure 3 (Barber and Archer 2001; Barter et al. 2003).

With hind sight there were two other aspects of our analysis of the electron density map of the CP47$\mathrm{RC}$ complex which we should have recognized. We identified in Rhee et al. (1998), but did not report, that two helices in our structure were likely to be the subunits of cytochrome b559 (Cyt b559) because there was sufficient density between them to accommodate a heme group. Kyong-He Rhee, however, did include this assignment in her PhD thesis (Rhee 1998) which was confirmed by X-ray structure analysis (Zouni et al. 2001). The other assignment relates to the two extra Chls of the D1 and D2 proteins which were predicted to be ligated to their B-helices at His118 and later were visualized in the X-ray structures (Zouni et al. 2001; Kamiya and Shen 2003). We observed the density for these two extra Chls but incorrectly interpreted them as possible transmembrane helices. Therefore the CP47-RC complex contains five transmembrane helices of low molecular weight subunits, not seven as originally reported. From N-terminal analyses and mass spectrometry we concluded that these five low molecular weight proteins are the $\alpha$ - and $\beta$-subunits of Cyt b559, PsbI, PsbT $\mathrm{C}$ and PsbW (Zheleva et al. 1998).

\section{$R C$ core dimer}

Although the 3-D analysis of the CP47-RC subcomplex had been highly successful, I was frustrated by the fact that it was not a fully functional complex able to evolve oxygen. Thus with Ben Hankamer I took up the challenge to grow good 2-D crystals of the PS II core dimer. Using reconstitution procedures we were able to obtain rather good 2-D crystals which initially provided a low resolution 3-D model after analyzing negatively stained samples (Morris et al. 1997). With the arrival of a Phillips CM200 electron microscope at Imperial College with a field emission gun and cryo facilities, we were able to exploit further the potential of the 2-D crystals. Ed Morris conducted the cryo-EM and by 1999 we had obtained a projection map of the spinach core dimer at about $9 \AA$ (Hankamer et al. 1999). This was an important step since it established that CP43 was definitely located on the opposite 
Singlet states Charge separated states Charge separated states

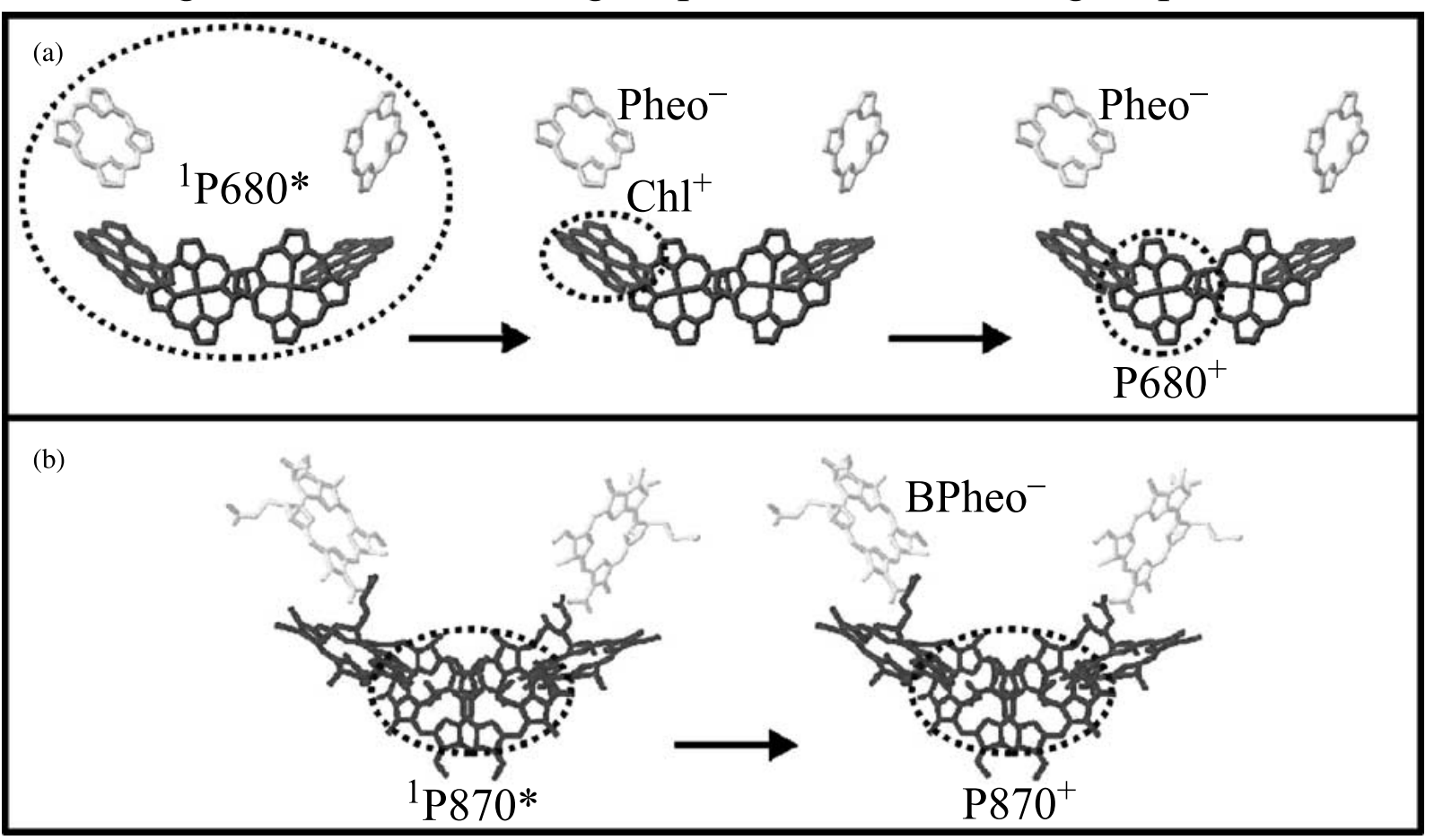

Figure 3. Schemes for primary charge separation in PS II (a) and purple bacteria (e.g., Rhodobacter sphaeroides), (b), emphasizing the distinct difference between the two systems. In the case of PS II the initial oxidant $\mathrm{Chl}^{+}$is thought to be the accessory chlorophyll bound to the D1 branch of the reaction centre while P680 ${ }^{+}$is assumed to be the chlorophyll ligated to D1His198 (taken from Barber and Archer 2001).

side of the D1/D2 proteins to CP47 and also revealed densities, which were not present in the earlier CP47RC map. From the very beginning I assumed that D1 was adjacent to $\mathrm{CP} 43$ based on the idea that CP43 becomes dislodged from PS II to allow the turnover of the D1 protein (Barbato et al. 1992). The X-ray models have since verified this positioning.

From 1999 onwards we worked hard to obtain a 3-D structure of the spinach PS II core dimer by merging data obtained from tilted crystals. Although by the summer of 2000 we had made good progress our work was somewhat over shadowed by the report at a Gordon Conference of a 3-D model of PS II at $3.8 \AA$. This model was calculated from X-ray diffraction data collected from crystals of PS II cores isolated from the thermophilic cyanobacterium Synechococcus elongatus (Zouni et al. 2001; see Witt, this issue). It was with some satisfaction that I noted that their model was consistent with our work. Although the Berlin group initially thought they were crystallizing a monomer (Zouni et al. 2000) it was clear that their PS II complex was dimeric and very similar to that described by us for spinach. Moreover their assignment of the transmembrane helices of D1, D2, CP43 and CP47 was also consistent with ours. They also observed that P680 was not a special pair and that CP47 bound 14 Chls. Of course the X-ray structure surpassed our efforts in that it was at a higher resolution and readily located the metal centers in the complex, especially the density of the Mn cluster. On returning to London from the Gordon Conference, I decided to complete our 3-D structure based on electron crystallography and publish it, which we did in 2001 (Hankamer et al. 2001a). This 3-D structure shown in Figure 4 remains the only higher plant model of PS II at a level of resolution sufficient to identify transmembrane helices. As shown in Figure 5, it is remarkably similar to the cyanobacterial PS II but there seems to be differences in the number and positioning of some of the low molecular weight proteins (Hankamer et al. 2001b; Barber 2002, 2003). At present, the resolution of the X-ray structures of Zouni et al. (2001) and Kamiya and Shen (2003) are not sufficient to assign the single transmembrane 


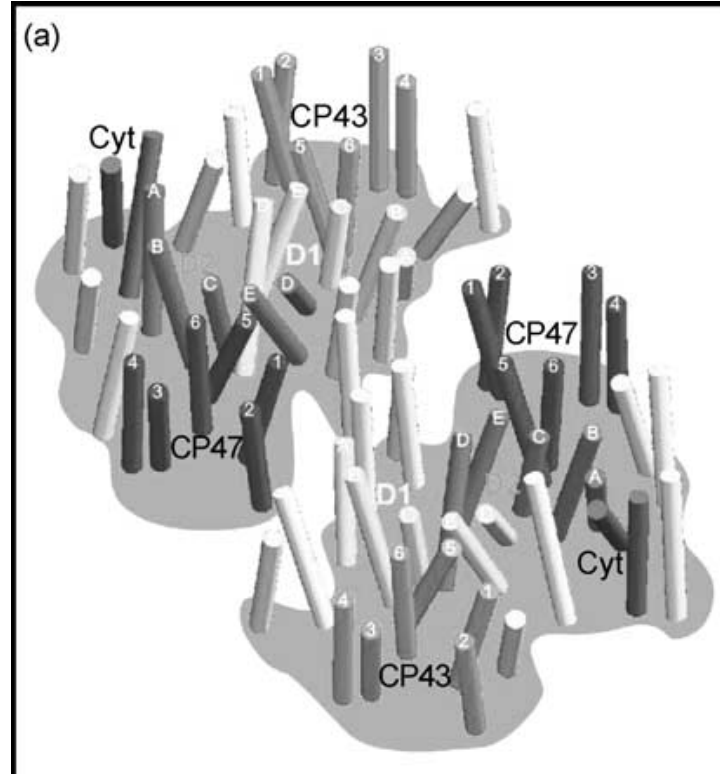

(b)

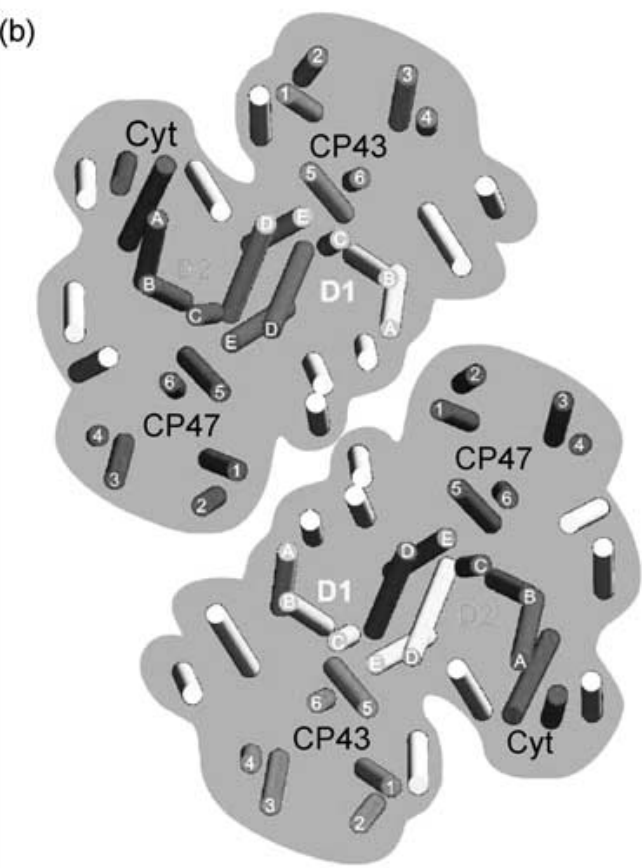

Figure 4. 3-D structural model of the PS II core dimer of spinach derived by electron crystallography (Hankamer et al. 2001a, b) showing transmembrane helices in (a) oblique view and (b) top view from the lumenal side.

helices to specific gene products and therefore the labeling shown in Figure 5 is tentative. Nevertheless, the two structures raise the question as to exactly what happens when some genes encoding the low molecular weight proteins have been inactivated. For example, together with Steve Mayes and Zhi-Hong Zhang, we had inactivated the genes encoding for PsbH, PsbK, PsbN as well as PsbO in Synechocystis 6803 (Mayes et al. 1991, 1993; Zhang et al. 1993). Others had inactivated other genes, for example $p s b$ I (Ikeuchi et al. 1995; Kunster et al. 1995). In all these cases PS II complex assembled and the mutants grew photoautotrophically. I ask myself, what plugs the 'hole' left by the absent protein?

The success of our work with higher plant PS II gives credit to those who pioneered electron crystallography as a technique for studying the structure of membrane proteins, particularly Richard Henderson and Nigel Unwin (1975). However the technique is limited and ultimately cannot compete with X-ray diffraction analyses of high ordered 3-D crystals. Thus the way forward is to obtain a high-resolution structure of PS II by X-ray crystallography. We need to reach a resolution sufficient to gain information about:

(i) Positioning and identification of side chains so as to elucidate the nature of the ligands that coordinate the cofactors, particularly the Mn-cluster, and explore the relationship between their redox properties and protein environment.

(ii) The nature of the base close to Tyrosine $\mathrm{Z}$ (Yz or TyrZ) of the D1 protein in order to understand the role of this redox active amino acid in water oxidation. Is this base the D1His 190 residue as proposed by site-directed mutagenesis (Debus 2001) and molecular modeling (e.g., Svensson et al. 1996)?

(iii) The distance between the water substrate molecules and TyrZ in order to assess whether the hydrogen-atom abstraction model of Jerry Babcock is feasible [Hoganson and Babcock (1997); see also Renger (2003)].

(iv) Factors that give rise to the high and low potential forms of cytochrome $b 559$.

(v) The nature of the photoinduced damage of D1 protein and the mechanisms of its selective degradation and replacement (see Adir et al. 2003).

Ultimately we would hope to obtain a structure at sufficient resolution to identify substrate water molecules and to obtain X-ray diffraction data for PS II in its various S-state configurations with the view of fully elucidating the chemistry of water oxidation.

\section{Supercomplexes}

Despite the obvious importance of X-ray crystallography, EM will continue to give information about 


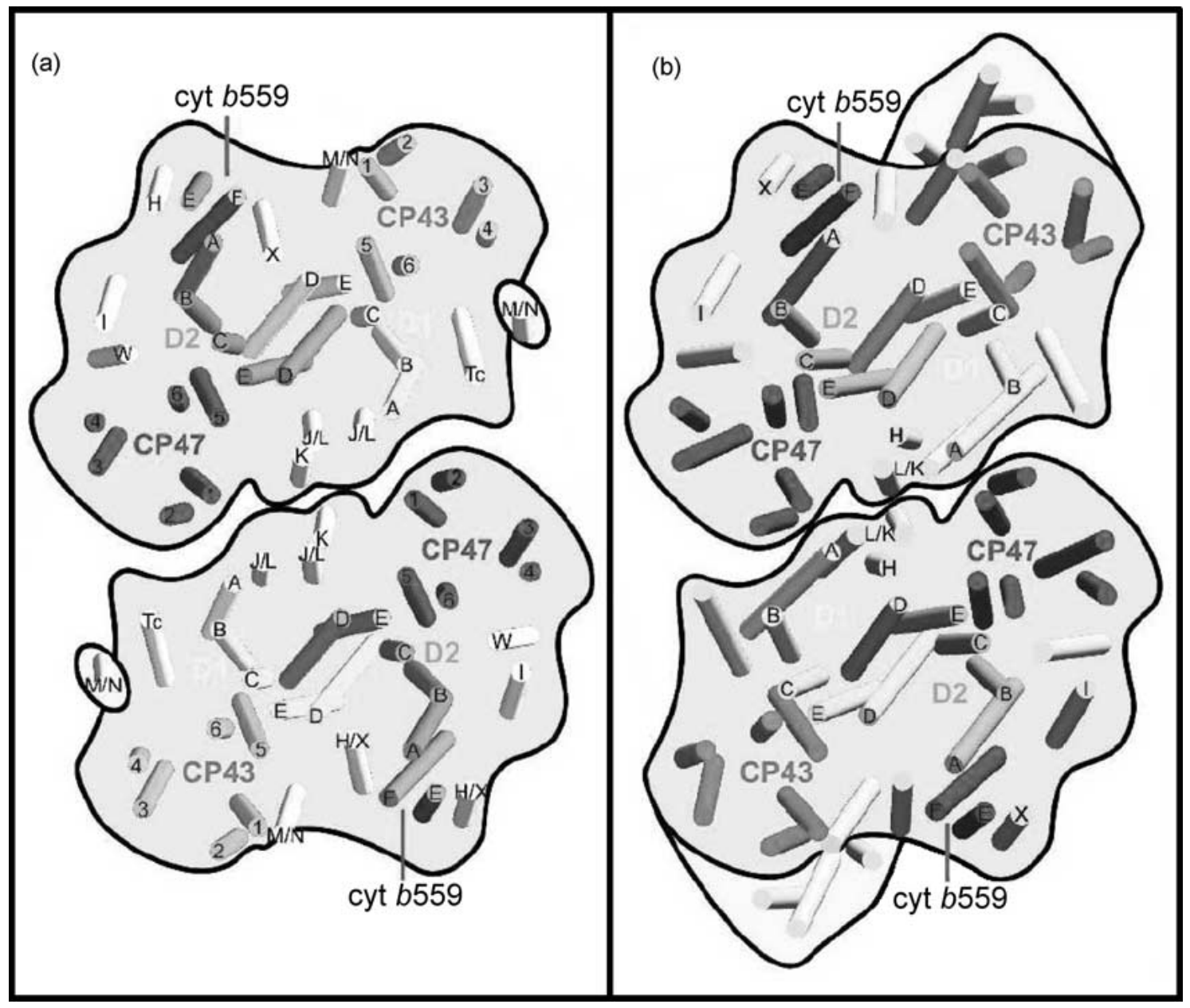

Figure 5. A comparison of the transmembrane helices in the core dimer of (a) spinach (Hankamer et al. 2001a) and (b) S. elongatus (Zouni et al. 2001). The helix organization of the D1 protein, D2, CP43, CP47, Cyt b559 and nine further helices of the small subunits seem to be identical in the two models. The labeling of small subunits has been made, tentatively, for spinach (Hankamer et al. 2001b) and for S. elongatus (Zouni et al. 2001).

the structural properties of PS II. It can provide a structural framework in which to incorporate high resolution X-ray data and thus explore the organization of macromolecular systems. With the help of Jon Nield in particular, I focused on elucidating the 3-D structure of the LHC II-PS II supercomplex that he, with Ben Hankamer, had isolated and biochemically characterized during his PhD studies. Today we have a $17 \AA$ 3-D model determined by cryo-EM (i.e., in the absence of electron dense stain) and used it to investigate how LHC II trimers may interact with the RC core dimer (Nield et al. 2000a, b) (see Figure 6) as well as gain a glimpse of the organization of the extrinsic proteins of the oxygen evolving complex (OEC) attached to the lumenal surface of plant PS II (Nield et al. 2002). Kamiya and Shen (2003) have identified the three extrinsic subunits of cyanobacteria and most of the loop structures of CP43 and CP47 in their $3.7 \AA$ structure of PS II.

The EM approach has also allowed us to discover that PS I can form a supercomplex with a PS II-like protein. During his PhD studies, Tom Bibby was looking for a modified form of PS II, which may form when cyanobacteria experience iron deficiency. Using Synechocystis Pasteur Culture Collection (PCC) 6803 I had hypothesized that the product of the ironstress-induced isiA gene could replace CP43 in normal PS II so as to convert it from a water oxidase to a 


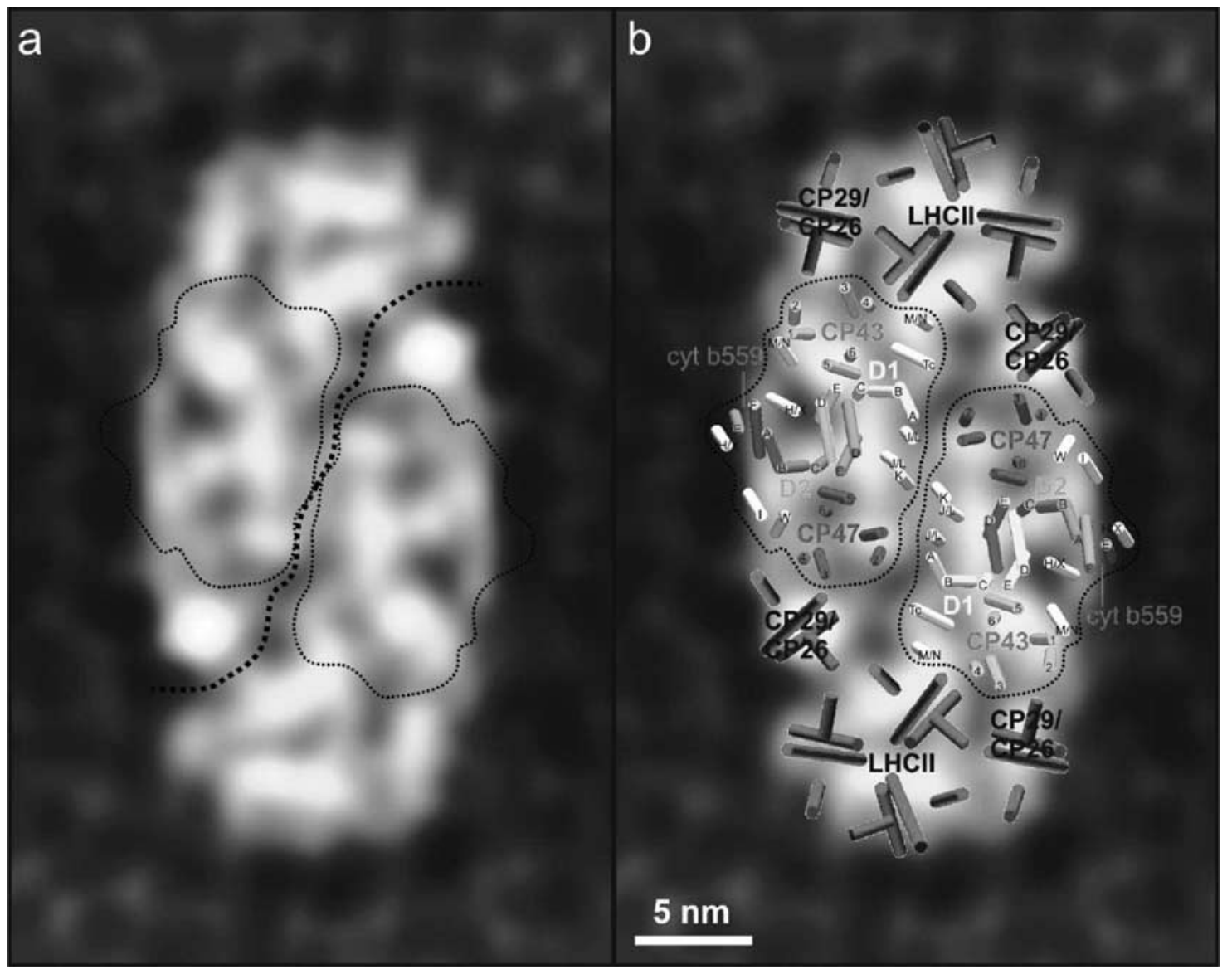

Figure 6. The relationship between the transmembrane helices of the central PS II core dimer and those of the outer antenna system of the LHCII-PS II supercomplex of spinach based on a combination of electron crystallographic and single particle analyses. (a) 2-D top-view projection derived from a $17 \AA$ 3-D map of the LHCII-PS II supercomplex obtained by cryo-EM showing the transmembrane domain (Nield et al. 2000c). The large dotted line separates the two monomers that make up the supercomplex and the fine dotted lines outline the central position of the core dimer. (b) Helices of the spinach core dimer from Figure 4a and the antenna Cab proteins, Lhcb1,2,4 (CP29) and 5 (CP26), based on the structure of the LHCII (Kühlbrandt et al. 1994), incorporated into the projection shown in (a) along the lines of previous modeling, but with modifications (Nield et al. 2000a, b; Hankamer et al. 2001a, b). Of special note is that according to the modeling, a group of two low molecular weight subunits (tentatively labeled $\mathrm{T}_{\mathrm{C}}$ and $\mathrm{M} / \mathrm{N}$ ) adjacent to helix $\mathrm{B}$ of the $\mathrm{D} 1$ protein seems to form a structural link to the LHCII trimer. In contrast S. elongatus has only one transmembrane helix assigned to this region (see Figure 5b).

plastocyanin oxidase. The isiA gene product is very similar to CP43 except it lacks the large loop joining transmembrane helices 5 and 6 . For this reason it is often called $\mathrm{CP} 43^{\prime}$. Was it therefore possible that CP43' could replace CP43 and prevent the binding of OEC proteins? If so then perhaps $\mathrm{P} 60^{+}$would be reduced by plastocyanin and facilitate cyclic electron flow similar to that which occurs in purple photosynthetic bacteria. Such a cycle would generate a $\Delta \mathrm{pH}$ across the thylakoid membrane and help the organism to survive under iron stress conditions when the level of PS I drops significantly due to poor supply of iron.
Tom Bibby did not find this hypothetical, modified form of PS II but his efforts resulted in the discovery of a supercomplex with 18 subunits of $\mathrm{CP} 43^{\prime}$, forming a light-harvesting antenna ring around the central trimeric PS I RC (Bibby et al. 2001a, b). At about the same time a similar structure was found in a species of Synechococcus (Boekema et al. 2001), also under iron-deficiency. Seeing this beautiful structure under the microscope was very exciting, an excitement which was enhanced when we showed that a very similar PS I light-harvesting antenna ring could be found in Prochlorococcus marinus SS120 (Bibby 
et al. 2001c). Prochlorococcus is probably the most abundant photosynthetic organism in the oceans and, like other prochlorophytes, contains a CP43'-like protein which binds chlorophyll $b$ as well as chlorophyll $a$ (known as Pcb proteins). We are continuing to combine EM, single-particle analysis and biochemical methodologies to study supercomplexes of PS I and PS II in a wide range of organisms which use the $\mathrm{CP} 43$-like proteins as light harvesting systems either under iron-rich or iron-deficient conditions (Bibby et al. 2003a, b). Iron deficiency, of course, is common in the natural environment and therefore the new structures we are looking at are physiologically important and abundant.

\section{A giant step forward}

Since writing the above text, my PS II journey has taken one giant step forward. In collaboration with my colleagues at Imperial College, London, So Iwata, Tina Iverson, Kristina Ferreira and Karim Maghlaoui, I have been lucky enough to obtain a complete and highly refined structure of PS II at a resolution sufficient to map over 2600 side chains and determine the position and orientations of 36 Chls and 7 carotenoids. In so doing we have revealed the details of the protein environments of the redox-active cofactors including the ligands for the metal center responsible for water oxidation. All but one of the low molecular weight subunits have now been assigned (Figure 7a). The details of this work have recently been published (Ferreira et al. 2004). Suffice to say that there are many facets of PS II function, which can now be addressed against a structural background, that hitherto was not possible. Here it seems appropriate that I should address the specific points that I raised in the section 'RC core dimer' before obtaining this new structure of PS II.

We have concluded that the metal center is composed of a cubane-like $\mathrm{Mn}_{3} \mathrm{CaO}_{4}$ cluster linked to a fourth $\mathrm{Mn}$ ion by a mono- $\mu$-oxo bridge (Figure 7b). The three Mn ions of this cubane-like structure have protein ligands including, surprisingly, one provided by the large extrinsic loop of CP43 (D1 Asp342, D1 His332, D1 Glu189 and CP43 Glu354). Water oxidation probably occurs at the fourth Mn ion having two protein ligands (D1 Glu333 and D1 Asp170). The $\mathrm{Ca}^{2+}$ within the cubane-like structure has three $\mu$-oxo ligands but no direct protein ligands although D1 Ala344 comes close to it. Many of these pro- tein ligands have been predicted by a wide range of excellent mutational studies reviewed by Rick Debus (2001) and Bruce Diner (2001). The proposed structure for the metal center is compatible with a mechanism of water oxidation in which a highly electrophilic oxo or oxyl radical, formed at the active $\mathrm{Mn}$ ion, undergoes nucleophilic attack by the oxygen of the second substrate water molecule contained within the coordination sphere of the $\mathrm{Ca}^{2+}$ along the lines of that suggested by Per Siegbahn (2002), Gary Brudvig (Vrettos et al. 2001) and Vincent Pecoraro et al. (1998). The structure we have proposed for the metal center is attractive because of its robustness and tolerance to ligand exchange. However, future studies are required to improve the resolution of our model and to investigate any structural changes that occur in the higher S-states.

Our structure is of sufficient reliability to conclude that D1 His190 is in hydrogen bonding distance to TyrZ as would be required for the latter to be oxidized by $\mathrm{P}^{\circ} 80^{+}$. The adjacent D1 Glu189 is not hydrogen bonded to D1 His190 but forms a protein ligand for one of the $\mathrm{Mn}$ in the cubane. There is no indication that water substrate protons would exit the active site via TyrZ as proposed by Babcock and colleagues (Hoganson and Babcock 1997) although the distance between the substrate water molecules in the active center and $\mathrm{Tyr}_{\mathrm{Z}}$ is sufficiently short for hydrogen bonding interactions. We have identified a potential proton channel leading from the active site involving a number of polar residues but this channel is almost on the opposite side to the electron transfer pathway and involves D1 Asp61, D1 Glu65, D2 Glu312 and D2 Lys317. It is possible, however, that Tyr $_{Z}$ could act as a proton acceptor at the $S_{4}$ to $S_{0}$ step of the S-state cycle and in this way aid deprotonation of the second substrate water molecule associated with $\mathrm{Ca}^{2+}$.

Of the many other details of the structure none of them help to explain the remaining points which I raised in the section ' $\mathrm{RC}$ core dimer', namely the factors which give rise to the high-and lowpotential forms of Cyt b559 and to the mechanism of D1 protein turnover. Perhaps future studies on PS II complexes, which have been photoinhibited prior to crystallization, will help to resolve these more dynamic aspects of PS II. It is of note, however, that the PsbO protein bridges the two monomers within the dimer and could play a role in D1 protein turnover by detaching and inducing monomerization. 


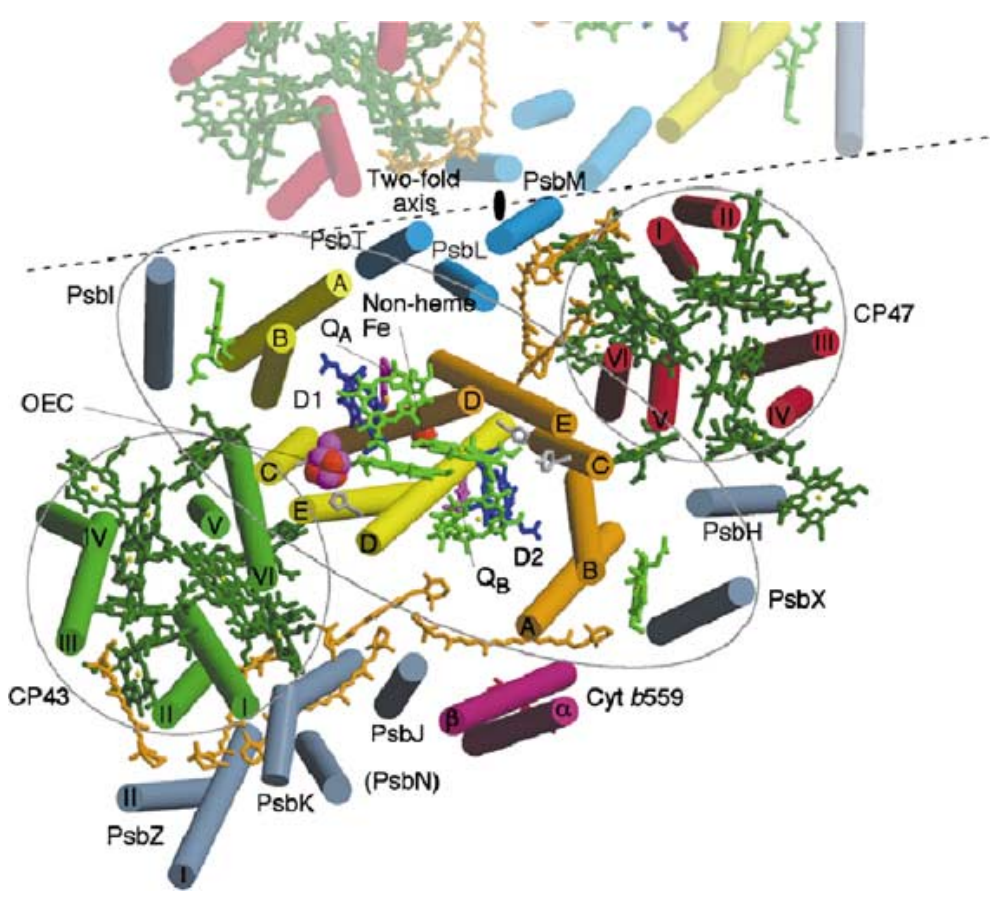

b

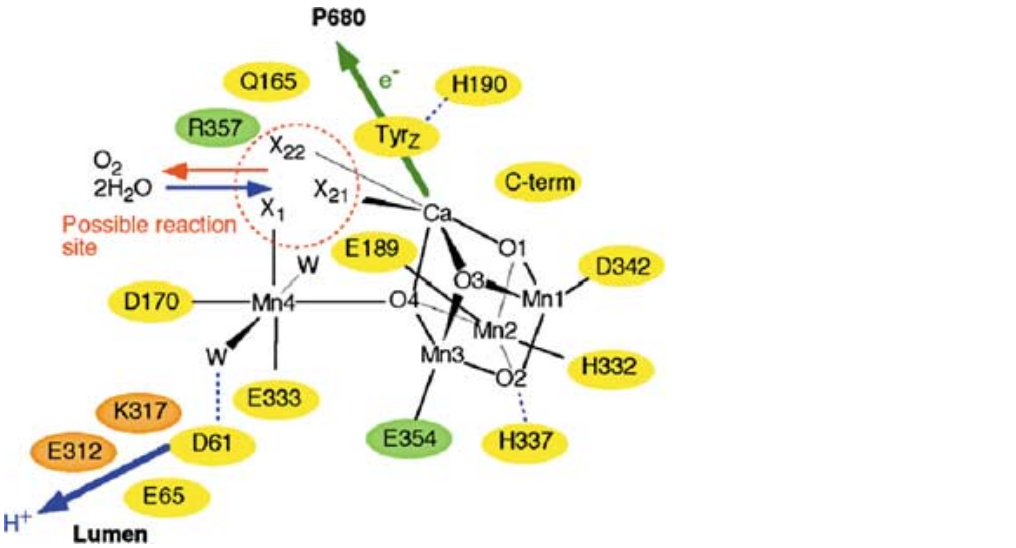

Figure 7. (a) View of the PS II monomer along the membrane normal from the lumenal side showing the assignment of the various subunits. One low molecular weight transmembrane helix is tentatively labeled as PsbN. A part of the other monomer in the dimer is shown to emphasize the region of monomer/monomer interaction along the dotted line. Also shown are the assigned 36 chlorophylls (6 binding to D1/D2, 16 to CP47 and 14 to CP43) and 7 carotenoids. The pseudo two-fold axis is perpendicular to the membrane plane passing through the non-heme Fe relates the transmembrane helices of the D1/D2 heterodimer, the low molecular weight subunits, PsbI and PsbX, and CP43 and CP47, as emphasized by the black circles around these subunits. The metal cluster of the oxygen evolving center is shown as red (oxygen atoms), magenta (Mn ions) and cyan $\left(\mathrm{Ca}^{2+}\right)$ balls and is located on the D1 side of the complex. Helices are represented as cylinders with D1 in yellow, D2 in orange, CP47 in red, CP43 in green, cyt b559 in wine red, PsbL, PsbM and PsbT in medium blue, and PsbH, PsbI, PsbJ, PsbK, PsbX, PsbZ and the putative PsbN in grey. The extrinsic proteins are PsbO in blue, PsbU in magenta and PsbV in cyan. Chlorophylls of the D1/D2 reaction center are light green, pheophytins are blue, chlorophylls of the antenna complexes are dark green, $\beta$-carotenes are in orange, hemes are in red, non-heme $\mathrm{Fe}$ is red, $\mathrm{Q}_{\mathrm{A}}$ and $\mathrm{Q}_{\mathrm{B}}$ are magenta. (b) A diagrammatic representation of the cubane-like $\mathrm{Mn}_{3} \mathrm{CaO}_{4}$ cluster bridged to a fourth $\mathrm{Mn}$ ion by a $\mu$-oxo bridge indicating the various protein ligands where yellow represents D1 residues, orange D2 residues, and green $\mathrm{CP} 43$ residues. The positioning of the $\mathrm{Mn}$ ions and $\mathrm{Ca}^{2+}$ are based on anomalous diffraction data and Fourier difference calculations. The cubane-like structure provides three oxo-ligands for the $\mathrm{Ca}^{2+}$ and three of the four $\mathrm{Mn}$ ions (Mn1, Mn2 and Mn3). The fourth $\mathrm{Mn}$ (Mn4) is probably bound to the high affinity site and is actively involved in water oxidation chemistry by binding one of the substrate water molecules. The other water substrate molecule probably binds to the calcium as indicated. The ligand denoted $\mathrm{X}$ could be chloride. $\mathrm{H}^{+} /$water channel leading from and to the catalytic center is identified and is on the opposite side of the metal cluster to that of the electron transfer pathway to P680. The overall figure is based on the X-ray structure of Ferreira et al. (2004) and (b) is a modification of the scheme given in this paper to emphasize the possible sites for substrate water binding. For a color version of this figure, see color section in the front of the issue. 


\section{Final comments}

There is no question that our progress in understanding the structure of PS II has taken a dramatic step forward over the past few years and it has been a privilege to have been involved in some of this progress. I am sure that X-ray crystallography will soon provide us with the level of detail needed to fully elucidate the mechanisms of the 'engine of life.' Its appearance about 2.5 billion years ago was indeed the 'big bang' of evolution but how did it evolve from a purple bacterial-like RC? (For a discussion on evolution, see Olson and Blankenship, this issue.) No doubt new microorganisms will be found which will help us to fill the gap between the anoxygenic and oxygenic systems. Is there a PS IIlike RC complex which catalyzes light driven cyclic electron flow involving the cytochrome $b_{6} f$ complex? Does, for example, the ' $\mathrm{CP} 43^{\prime} / \mathrm{D} 1 / \mathrm{D} 2 / \mathrm{CP} 47$ ' complex exist as we hypothesized when Tom Bibby started his $\mathrm{PhD}$ project? If so, does it act as a plastocyanin/Cyt $c_{6}$ oxidase? Dan Arnon was very keen about the idea of a plastocyanin driven cyclic pathway around PS II (Arnon and Tang 1989) which was the motivation behind the experiments I conducted with him when I visited Berkeley in 1990 for a 3month study leave (Arnon and Barber 1990). Clearly such a cycle cannot occur when the Mn-cluster and extrinsic proteins are present and $\mathrm{P} 60^{+}$is shielded from any electron donors other than water. But how did the Mn-cluster and its associated 'protein shield' evolve? My own recent exploration of various types of oxyphotobacteria has opened my eyes to the level of diversity that exists in the natural environment. Who would have guessed, for example, that a Chl $d$ containing RC existed as in the case of that recently discovered in Acaryochloris marina (Miyashita et al. 1996). Instead of having a P700 composed of Chl $a$ it has $\mathrm{P} 740$, composed of $\mathrm{Chl} d$, as its primary donor ( $\mathrm{Hu}$ et al. 1998) and it remains an open question whether Chl $d$ acts as a primary donor in PS II in this organism. If it does, then this will stimulate a serious debate about the thermodynamics of water oxidation because the redox energy available will be less than that provided by Chl $a$. Then there has been the discovery that the aerobic purple photosynthetic bacterium Acidiphilium rubrum uses Zn-bacteriochlorophyll instead of Mg-bacteriochlorophyll (Wakoo et al. 1996). It seems to me that there are many more exciting discoveries to be made as we cast our net more broadly for new experimental systems.
Along with these new discoveries will come the complete understanding of the chemistry of water oxidation which, with the new structural information, is now in sight.

\section{Acknowledgments}

My PS II journey would not have been possible if I had not been continuously funded by the UK research councils (Science Research Council, Agriculture and Food Research Council, and Biotechnology and Biological Sciences Research Council) and without the input of dedicated and talented PhD students, post-doctoral associates and academic visitors to my laboratory at Imperial College as well as numerous collaborations with colleagues in other laboratories. It is impossible to name the extensive list of those who have contributed but I particularly wish to acknowledge my very long collaboration with Alison Telfer (Figure 8) who joined my group as a post-doc in 1972 and who has survived 31 years of dealing with me. I also wish to give special recognition to Ben Hankamer, Jon Nield, Ed Morris and Tom Bibby (Figure 9) who, along with Egbert Boekema, Werner Kühlbrandt, Tina Iverson and So Iwata, have played an important role in my recent structural studies. There have been, of course, many excellent graduate students, Bill Varley, Mike Hipkins, John Mills, Peter Nixon, Julian Whitelegge, William Newell, Bob Ford, Herb Nakatani, Roy Mansfield, Steve Mayes, Cathy Shipton, Katie Cook, Paula Booth, James Durrant to name just a few. My more recent graduate students

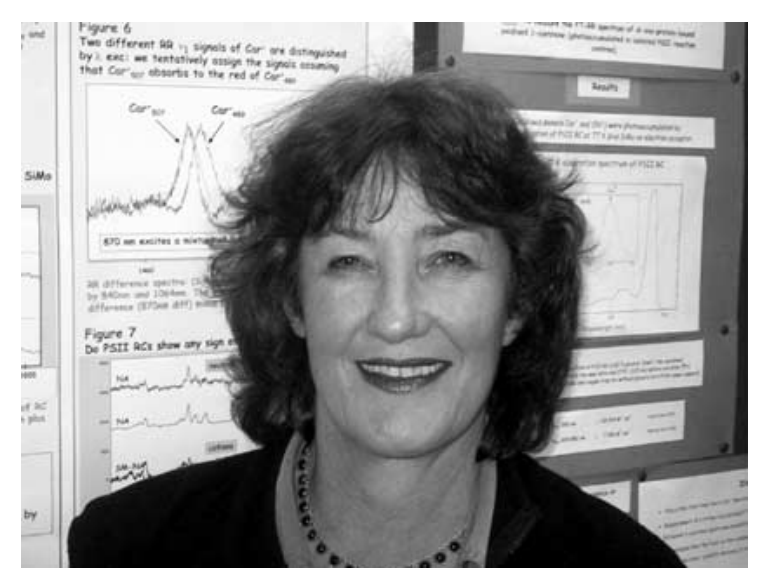

Figure 8. Alison Telfer, a long-time associate, photographed in 2003. 


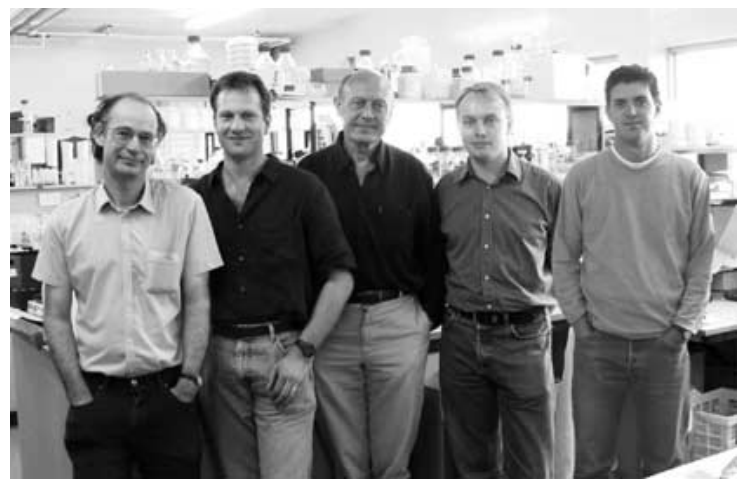

Figure 9. A photograph taken in my laboratory at Imperial College, London in 2002. Left to right: Ed Morris, Ben Hankamer, the author, Jon Nield and Tom Bibby.

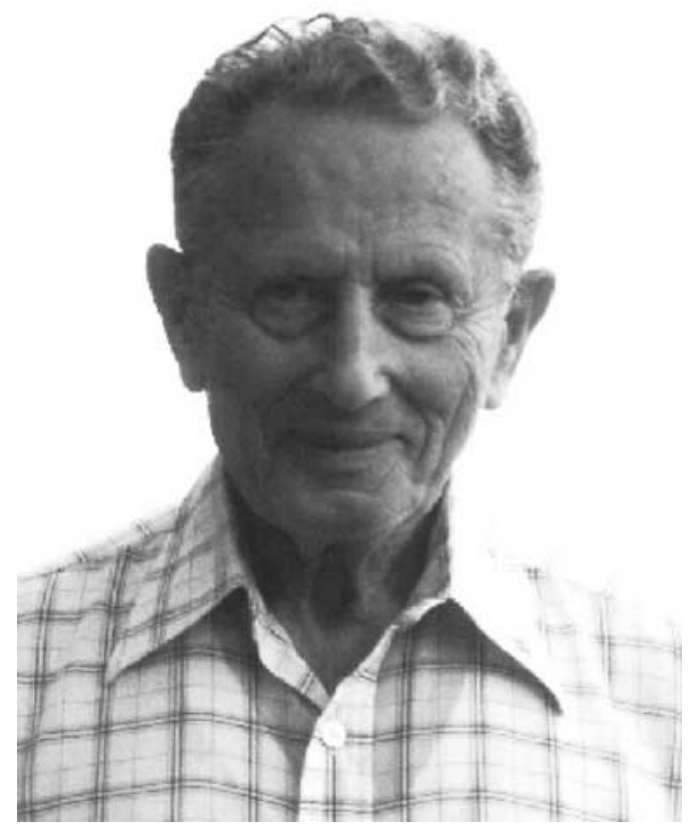

Figure 10. A photograph of Professor Dan Arnon taken in Palma de Mallorca when he lectured on the Advanced Course in Photosynthesis entitled Trends in Photosynthesis Research in September 1990, which resulted in his last publication (Arnon 1992).

in the final stages of their studies are James Duncan, Kristina Ferreira, James Berry and Karim Maghlaoui. These and other PhD students, post-docs and visitors have all contributed to the vitality of my laboratory and my research career and I thank and applaud them all.

During my academic career I never managed to take a full year sabbatical but of the short study leaves I took my most memorable was spent in Berkeley at the University of California, Berkeley, in 1999, when I enjoyed endless hours discussing science and the meaning of life with Dan Arnon (Figure 10) as well as

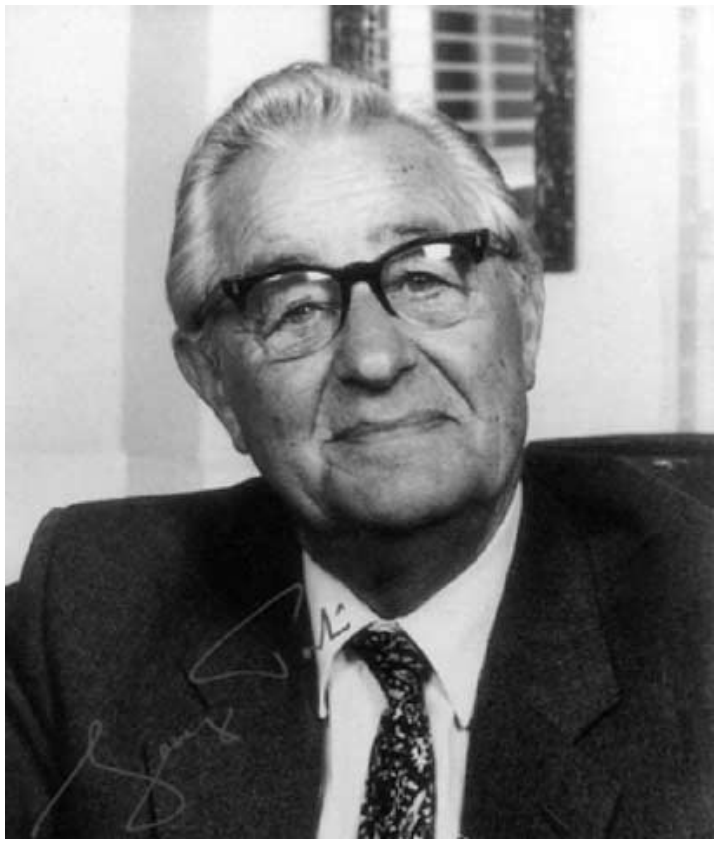

Figure 11. A photograph of Professor Lord Porter OM, Nobel Laureate, with whom the author collaborated over a period of 30 years. Perhaps the most classical study of this collaboration was the first ever time-resolving of energy transfer in a photosynthetic light-harvesting system, namely the transfer of energy from phycobiliproteins to PS II in the red alga Porphyridium cruentum (Porter et al. 1978). (Also see Brody 2002; and Mimuro 2002.)

exploring ideas about plastocyanin as a donor to PS II. The Royal Institution also offered me an additional environment to conduct research where George Porter (Figure 11) provided inspiration and friendship and gave me the opportunity to investigate the reactions of PS II using ultrafast spectroscopy.

This paper was read by four reviewers, and edited by Govindjee. I thank them all for many suggestions that has improved my presentation.

\section{References}

Adir N, Zer H, Shochat I and Ohad I (2003) Photoinhibition - a historical perspective. Photosynth Res 76: 343-370

Albertsson PA (2001) A quantitative model of the domain structure of the photosynthetic membrane. Trends Plant Sci (TIPS) 6: 349-353

Albertsson PA (2003) The contribution of photosynthetic pigments to the development of biochemical separation methods: 1900-1980. Photosynth Res 76: 217-225

Allen JF (2002) Plastoquinone redox control of chloroplast thylakoid protein phosphorylation and distribution of excitation energy between photosystems: discovery, background, implications. Photosynth Res 73: 139-148 
Anderson JM (2002) Changing concepts about the distribution of Photosystems I and II between grana-appressed and stromaexposed thylakoid membranes. Photosynth Res 73: 157-164

Anderson JM and Andersson B (1981) Lateral organization of the chlorophyll-protein complexes of spinach thylakoids. In: Akoyunoglou G (ed) Photosynthesis, Vol III, Structure and Molecular Organisation of the Photosynthetic Apparatus, pp 23-31. Balaban International Science Services, Philadelphia, Pennsylvania

Andersson B (1978) Separation of chloroplast lamella fragments by phase partition, including the isolation of inside-out vesicles. $\mathrm{PhD}$ thesis. Lund, Sweden

Andersson B and Anderson JM (1980) Lateral heterogeneity in the distribution of the chlorophyll-protein complexes of the thylakoid membranes of spinach chloroplasts. Biochim Biophys Acta 593: 427-440

Arnold WA and Azzi J (1971) Electric field and chloroplast membranes. In: Manson LA (ed) Biomembranes, Vol 2, pp 189-191. Plenum Press, New York

Arnold WA and Davidson JB (1954) The identity of the fluorescence and delayed light emission spectra in Chlorella. J Gen Physiol 37: 677-684

Arnold WA and Davidson JB (1963) The decay of delayed light at short times. In: Kok B and Jagendorf AT (eds) Photosynthetic Mechanisms of Green Plants, pp 689-700. National Academy of Sciences-National Research Council, Washington DC

Arnold WA and Sherwood H (1957) Are chloroplasts semiconductors? Proc Natl Acad Sci USA 43: 105-114

Arnon DI (1992) Conceptual evolution in photosynthesis: the quest for a common denominator. In: Barber J, Guerroro MG and Medrano H (eds) Trends in Photosynthesis Research, pp 13-25. Intercept, Andover, UK

Arnon DI and Barber J (1990) Photoreduction of $\mathrm{NADP}^{+}$by isolated reaction centers of Photosystem II: requirement for plastocyanin. Proc Natl Acad Sci USA 87: 5930-5934

Arnon DI and Tang GMS (1989) Photoreduction of NADP ${ }^{+}$by a choloroplast Photosystem II preparation: effect of light intensity. FEBS Lett 25: 253-256

Barbato R, Friso G, Rigoni F, Dalla Vecchia F and Giacometti GM (1992) Structural changes and lateral redistribution of Photosystem II during donor side photoinhibition of thylakoids. J Cell Biol 119: 325-335

Barber J (1972a) A method of estimating the magnitude of the light-induced electrical potential across the thylakoid membrane. FEBS Lett 20: 251-254

Barber J (1972b) Stimulation of millisecond delayed light emission by $\mathrm{KCl}$ and $\mathrm{NaCl}$ gradients as a means of investigating the ionic permeability properties of the thylakoid membrane. Biochim Biophys Acta 275: 105-116

Barber J (1976) Ionic regulation in intact chloroplasts and its effect on primary photosynthetic processes. In: Barber J (ed) The Intact Chloroplast, Vol 1, Topics in Photosynthesis, pp 89-134. Elsevier, Amsterdam

Barber J (1979) Energy transfer and its dependence on membrane properties. In: Chlorophyll Organisation and Energy Transfer in Photosynthesis. Ciba Foundation Symp. London, Meeting No. 61 (Special Issue), pp 283-304. Elsevier, Amsterdam

Barber J (1980a) An explanation for the relationship between saltinduced thylakoid stacking and chlorophyll fluorescence changes associated with changes in spillover of energy from Photosystem II to Photosystem I. FEBS Lett 118: 1-10

Barber J (1980b) Membrane surface charges and potentials in relation to photosynthesis. Biochim Biophys Acta 594: 253-308
Barber J (1982) Influence of surface charges on thylakoid structure and function. Ann Rev Plant Physiol 33: 261-295

Barber J (1994) Molecular basis of the vulnerability of Photosystem II to damage by light. Aust J Plant Physiol 22: 201-208

Barber J (2001) P680: what is it and where is it? Bioelectrochemistry $55: 135-138$

Barber J (2002) Photosystem II: a multisubunit membrane protein that oxidizes water. Curr Opin Struct Biol 12: 523-530

Barber J (2003) Photosystem II: the engine of life. Biophys Quart Rev 36: 71-89

Barber J and Archer MD (2001) P680, the primary electron donor of PS II. Photochem Photobiol A Chemistry 142: 97-106

Barber J and Chow WS (1979) A mechanism for controlling the stacking and unstacking of chloroplast thylakoid membranes. FEBS Lett 105: 5-10

Barber J and Kraan GPB (1970) Salt induced light emission from chloroplasts. Biochim Biophys Acta 197: 49-95

Barber J and Searle GFW (1978) Cation induced increase in chlorophyll fluorescence yield and the effect of electrical charge. FEBS Lett 92: 5-8

Barber J and Searle GFW (1979) Double layer theory and the effect of $\mathrm{pH}$ on cation-induced chlorophyll fluorescence. FEBS Lett 103: 241-245

Barber J, Mills JD and Nicholson J (1974a) Studies with cation specific ionophores show that within the intact chloroplast $\mathrm{Mg}^{2+}$ acts as the main exchange cation for $\mathrm{H}^{+}$-pumping. FEBS Lett 49: 106-109

Barber J, Telfer A, Mills JD and Barber J (1974b) Slow chlorophyll fluorescence changes in isolated intact chloroplasts. Evidence for cation control. In: Avron M (ed) Proceedings III International Congress Photosynthesis, pp 53-63. Elsevier, Amsterdam

Barber J, Telfer A and Nicolson J (1974c) Evidence for divalent cation movement within isolated whole chloroplasts from studies with ionophore A23187. Biochim Biophys Acta 357: 161-165

Barber J, Mills JD and Love A (1977a) Electrical diffuse layers and their influence on photosynthetic processes. FEBS Lett 74: 174-181

Barber J, Mauro S and Lannoye R (1977b) The relationship between the yield factors for prompt and delayed fluorescence. FEBS Lett 80: 449-454

Barber J, Rubin BT and Chow WS (1981) Theoretical aspects of cation induced chlorophyll fluorescence and thylakoid stacking changes. In: Akoyunoglou G (ed) Photosynthesis, Vol I, Photophysical Processes - Membrane Energization, pp 397-405. Balaban International Science Services, Philadelphia, Pennsylvania

Barber J, Chapman DJ and Telfer A (1987) Characterisation of a photosystem two reaction centre isolated from the chloroplasts of Pisum sativum. FEBS Lett 220: 67-73

Barter LM, Durrant JR and Klug DR (2003) A quantitative structure-function relationship for Photosystem II reaction center: supermolecular behaviour in natural photosynthesis. Proc Natl Acad Sci USA 100: 946-951

Bassi R, Ghiretti-Magaldhi A, Tognon G, Giacometti GM and Miller KR (1989) Two dimensional crystals of the Photosystem II reaction center complex from higher plants. Eur J Cell Biol 50: 84-93

Berthold DA, Babcock GT and Yocum CF (1981) A highly resolved, oxygen-evolving Photosystem II preparation from spinach thylakoid membranes: EPR and electron transport properties. FEBS Lett 134: 231-234

Bibby TS, Nield J and Barber J (2001a) Iron deficiency induces formation of an antenna ring around trimeric Photosystem I in cyanobacteria. Nature 412: 743-745 
Bibby TS, Nield J and Barber J (2001b) 3D model and characterization of the iron stress induced CP43'-PS I supercomplex isolated from the cyanobacteria Synechocystis PCC 6803. J Biol Chem 276: 43246-43252

Bibby TS, Nield J, Partensky F and Barber J (2001c) Oxyphotobacteria: antennae ring around Photosystem I. Nature 413: 590

Bibby TS, Mary I, Nield J, Partensky F and Barber J (2003a) Lowlight-adapted Prochlorococcus species possess specific antenna for each photosystem. Nature 424: 1051-1054

Bibby TS, Nield J, Chen M, Larkum AWA and Barber J (2003b) Structure of a Photosystem II supercomplex isolated from Prochloron didemni retaining its chlorophyll $a / b$ light-harvesting system. Proc Natl Acad Sci USA 100: 9050-9054

Boardman NK and Anderson JM (1964) Isolation from spinach chloroplasts of particles containing different proportions of chlorophyll $a$ and chlorophyll $b$ and their possible role in the light reactions of photosynthesis. Nature 203: 166-167

Boekema EJ, Hankamer B, Bald D, Kruip J, Nield J, Boonstra AF, Barber J and Rögner M (1995) Supramolecular structure of the photosynthetic complex from green plants and cyanobacteria. Proc Natl Acad Sci USA 92: 175-179

Boekema EJ, Hifney A, Yakusheveska AE, Piotrowski M, Keegstra W, Berry S, Michel K-P, Pistorius EK and Kruip J (2001) A giant chlorophyll-protein complex induced by iron deficiency in cyanobacteria. Nature 412: 745-748

Bonaventura C and Myers J (1969) Fluorescence and oxygen evolution from Chlorella pyrenoidosa. Biochim Biophys Acta 189: 366-383

Briantais J-M, Vernotte C, Picaud M and Krause GH (1979) A quantitative study of the slow decline of chlorophyll $a$ fluorescence in isolated chloroplasts. Biochim Biophys Acta 548: $128-138$

Brody SS (2002) Fluorescence lifetime, yield, energy transfer and spectrum in photosynthesis, 1950-1960. Photosynth Res 73: $127-132$

Chapman DJ, Gounaris K and Barber J (1988) Electron transport properties of the isolated D1-D2-cytochrome b559 Photosystem two reaction centre. Biochim Biophys Acta 933: 423-431

Chow WS and Barber J (1980) Further studies of the relationship between cation-induced chlorophyll fluorescence and thylakoid membrane stacking changes. Biochim Biophys Acta 593: 149-157

Crystal B, Booth PJ, Klug DR, Barber J and Porter G (1989) Resolution of a long lived fluorescence component from D1-D2-cytochrome b559 reaction centres. FEBS Lett 249: 75-78

Debus RJ (2001) Amino acid residues that modulate the properties of tyrosine $\mathrm{Y}_{\mathrm{Z}}$ and the manganese cluster in the water oxidizing complex of Photosystem II. Biochim Biophys Acta 1503: 164-186

Dekker JP and van Grondelle R (2000) Primary charge separation in Photosystem II. Photosynth Res 63: 195-208

De Grooth BG and van Gorkom HJ (1981) External electric field effect on prompt and delayed fluorescence in chloroplasts. Biochim Biophys Acta 635: 445-456

Diner BA (2001) Amino acid residues involved in the coordination and assembly of the Mn cluster of PS II. Proton-coupled electron transport of the redox-active tyrosines and its relationship to water oxidation. Biochim Biophys Acta 1503: 147-163

Diner BA, Schlodder E, Nixon PJ, Coleman WJ, Rappaport F, Lavergne J, Vermaas WFJ and Chisholm DA (2001) Site directed mutations at D1-His 189 and D2His197 of PS II in Synechocystis PCC 6803: sites of primary charge separation and cation and triplet stabilization. Biochemistry 40: 9265-9281

Döring G, Stiehl H and Witt HT (1967) A second chlorophyll reaction in the electron chain of photosynthesis. Z Naturforsch $22 \mathrm{~b}$ : 639-644

Durrant JR, Giorgi LB, Barber J, Klug DR and Porter G (1990) Characterisation of triplet states in isolated Photosystem II reaction centres: oxygen quenching as a mechanism for photodamage. Biochim Biophys Acta 1017: 167-175

Durrant JR, Klug DR, Kwa SLS, van Grondelle R, Porter G and Dekker JP (1995) A multimer model for P680, the primary electron donor of Photosystem II. Proc Natl Acad Sci USA 92: 4798-4802

Duysens LNM and Sweers HE (1963) Mechanism of two photochemical reactions in algae as studied by means of fluorescence. In: Ashida J (ed) Studies on Microalgae and Photosynthetic Bacteria, pp 353-372. University of Tokyo Press, Tokyo

Ellenson JL and Sauer K (1976) The electrophotoluminescence of chloroplasts. Photochem Photobiol 23: 113-123

Ferreira KN, Iverson TM, Maghlaoui K, Barber J and Iwata S (2004) Architecture of the photosynthetic oxygen-evolving center. Science 303: 1831-1837

Gounaris K, Chapman DJ, Booth P, Crystall B, Giorgi LB, Klug DR, Porter G and Barber J (1990) Comparison of the D1/D2/cyt b559 reaction centre complex of photosystem two isolated by two different methods. FEBS Lett 265: 88-92

Govindjee (1995) Sixty-three years since Kautsky: chlorophyll $a$ fluorescence. Aust J Plant Physiol 22: 131-161

Govindjee and Papageorgiou G (1971) Chlorophyll fluorescence and photosynthesis: fluorescence transients. In: Giese AC (ed) Photophysiology, Vol VI, pp 1-46. Academic Press, New York

Hankamer B, Barber J and Boekema EJ (1997a) Structure and membrane organization of PS II in green plants. Annu Rev Plant Phys Mol Biol 48: 641-671

Hankamer B, Nield J, Zheleva D, Boekema EJ, Jansson S and Barber J (1997b) Isolation and biochemical characterization of monomeric and dimeric PS II complexes from spinach and their relevance to the organization of Photosystem II in vivo. Eur J Biochem 243: 422-429

Hankamer B, Morris EP and Barber J (1999) Cryoelectron microscopy of photosystem two shows that CP43 and CP47 are located on opposite sides of the D1/D2 reaction centre proteins. Nature Struct Biol 6: 560-564

Hankamer B, Morris EP, Nield J, Gerle C and Barber J (2001a) Three dimensional structure of Photosystem II core dimer of higher plants determined by electron microscopy. J Struct Biol 135: 262-269

Hankamer B, Morris EP, Nield J, Carne A and Barber J (2001b) Subunit positioning and transmembrane helix organization in the core dimer of Photosystem II. FEBS Lett 504: 142-151

Henderson R and Unwin PNT (1975) Three-dimensional model of purple membrane obtained by electron microscopy. Nature 257 : 28-32

Hill R and Bendall F (1960) Function of two cytochrome components in chloroplasts: a working hypothesis. Nature 186: 136-137

Hipkins MF and Barber J (1974) Estimation of the activation energy for millisecond delayed fluorescence from uncoupled chloroplasts. FEBS Lett 42: 289-292

Hoganson CW and Babcock GT (1997) A metalloradical mechanism for the generation of oxygen from water in photosynthesis. Science 277: 1953-1956 
Holzenburg A, Bewley MC, Wilson FH, Nicolson WV and Ford RC (1993) Three-dimensional structure of Photosystem II. Nature 363: $470-472$

Homann P (1969) Cation effects on the fluorescence of isolated chloroplasts. Plant Physiol 44: 932-936

Hu Q, Miyashita H, Iwasaki I, Kurano N, Miyachi S, Iwaki M and Itoh S (1998) A Photosystem I reaction center driven by chlorophyll $d$ in oxygenic photosynthesis. Proc Natl Acad Sci USA 95: 13319-13323

Ikeuchi M, Shukla VK, Pakrasi HB and Inoue Y (1995) Directed inactivation of the $p c b$ I gene does not affect Photosystem II in cyanobacterium Synechocystis sp. PPP 6803. Mol Gen Genet 249: 622-628

Jackson JB and Crofts AR (1969) The high energy state in chromatophores from Rhodopseudomonas sphaeroides. FEBS Lett 4: 185-189

Jagendorf AT and Uribe E (1966) ATP formation caused by acidbase transition of spinach chloroplasts. Proc Natl Acad Sci USA 55: $170-177$

Joliot A and Joliot P (1964) Étude cinétique de la réaction photochimique libérant l'oxygène au cours de la photosynthèse. CR Acad Sci Paris 258: 4622-4625

Joliot P and Joliot A (2003) Excitation transfer between photosynthetic units: the 1964 experiment. Photosynth Res 76: 241-245

Kamiya N and Shen JR (2003) Crystal structure of oxygen-evolving Photosystem II from Thermosynechococcus vulcanus at $3.7 \AA$ resolution. Proc Natl Acad Sci USA 100: 98-102

Kautsky H, Appel N and Amann H (1960) Chlorophyll Fluorescenz und Kohlensäure Assimilation XIII. Die Fluorescenz Kurve und die Photochemie der Pflanze. Biochem Z 332: 277-292

Klug DR, Durrant JR and Barber J (1998) The entanglement of excitation energy transfer and electron transfer in the reaction centre of Photosystem II. Phil Trans R Soc London A 356: 449-464

Kok B and Cheniae G (1966) Kinetics and intermediates of the oxygen evolution step in photosynthesis In: Sanadi R (ed) Current Topics in Bioenergetics, Vol 1, pp 1-47. Academic Press, New York

Krause GH (1974) Changes in chlorophyll fluorescence in relation to light-dependent cation transfer across thylakoid membranes. Biochim Biophys Acta 333: 301-313

Krause GH, Vernotte C and Briantais J-M (1982) Photoinduced quenching of chlorophyll fluorescence in intact chloroplasts and algae, resolution into two components. Biochim Biophys Acta 679: 116-124

Krauß N, Schubert W-D, Klukas O, Fromme P, Witt HT and Saenger W (1996) Photosystem I at $4 \AA$ resolution represents the first structural model of a joint photosynthetic reaction centre and core antenna system. Nat Struct Biol 3: 965-973

Kühlbrandt W, Wang DN and Fujiyoshi Y (1994) Atomic model for plant light harvesting complex by electron crystallography. Nature 367: 614-621

Kunster P, Guardiola A, Takahashi Y and Rochaix JD (1995) A mutant strain of Chlamydomonas reinhardtii lacking the chloroplast Photosystem II $p s b$ I gene grows photoautotrophically. J Biol Chem 270: 9651-9654

Lavorel J (1959) Induction of fluorescence in quinone poisoned Chlorella. Plant Physiol 34: 204-209

Lavorel J (1968) Sur une relation entre fluorescence et luminescence dans les systemes photosynthetiques. Biochim Biophys Acta 153: 727-730
Lyon MK, Marr KM and Furcinitti PS (1993) Formation and characterization of two-dimensional crystals of Photosystem II. J Struct Biol 110: 133-140

Malkin S and Kok B (1966) Fluorescence induction studies in isolated chloroplast. I. Number of components involved in the reaction and quantum yields. Biochim Biophys Acta 126: 413-432

Marder JB, Chapman DJ, Telfer A, Nixon PJ and Barber J (1987) Identification of $p s b \mathrm{~A}$ and $p s b \mathrm{D}$ gene products, D1 and D2, as reaction centre proteins of Photosystem 2. Plant Mol Biol 8: 325-333

Mayes SR, Cook KM, Self SJ, Zhang ZH and Barber J (1991) Deletion of the gene encoding the PS II $33 \mathrm{kDa}$ protein from Synechocystis PCC 6803 does not inactivate water-splitting but increases vulnerability to photoinhibition. Biochim Biophys Acta 1060: $1-12$

Mayes SR, Dubbs JM, Vass I, Hideg E, Nagy L and Barber J (1993) Further characterization of the $p s b \mathrm{H}$ locus of Synechocystis sp. PCC 6803: inactivation of $p s b \mathrm{H}$ impairs $\mathrm{Q}_{\mathrm{A}}$ and $\mathrm{Q}_{\mathrm{B}}$ electron transport in photosystem 2. Biochemistry 32 : 1454-1465

Mayne BC and Clayton RK (1966) Luminescence of chlorophyll in spinach chloroplasts induced by acid-base transitions. Proc Natl Acad Sci USA 55: 494-497

McTavish H, Picorel R and Seibert M (1989) Stabilization of isolated Photosystem II reaction center complex in the dark and in the light using polyethylene glycol and an oxygen-scrubbing system. Plant Physiol 89: 452-456

Mills JD and Barber J (1975) Energy-dependent cation induced control of chlorophyll $a$ fluorescence in isolated intact chloroplasts. Arch Biochem Biophys 170: 306-314

Mimuro M (2002) Visualization of excitation energy transfer processes in plants and algae. Photosynth Res 73: 133-138

Mitchell P (1966) Chemiosmotic coupling in oxidative and photosynthetic phosphorylation. Biol Rev Cambridge Phil Soc 41: 445-502

Miyashita H, Ikemoto H, Kurano N, Adachi K, Chihara M and Miyachi S (1996) Chlorophyll $d$ as a major pigment. Nature 383: 402

Mohanty P, Braun BZ and Govindjee (1973) Light-induced slow changes in chlorophyll $a$ fluorescence in isolated chloroplasts: effects of magnesium and phenazine methosulfate. Biochim Biophys Acta 292: 459-476

Morris EP, Hankamer B, Zheleva D, Friso G and Barber J (1997) The 3D structure of a Photosystem II core complex determined by electron crystallography. Structure 5: 837-849

Munday JC and Govindjee (1969) Light-induced changes in the fluorescence yield of chlorophyll- $a$ in vivo III. The dip and the peak in fluorescence transients of Chorella pyrenoidosa. Biophys J 9: 1-21

Murakami S and Packer L (1971) The role of cations in the organization of chloroplast membranes. Arch Biochem Biophys 146: 337-347

Murata N (1969) Control of excitation energy transfer in photosynthesis I. Light-induced change of chlorophyll $a$ fluorescence. Biochim Biophys Acta 172: 242-251

Nakatani HY and Barber J (1980) Further studies of thylakoid membrane surface charges by particle electrophoresis. Biochim Biophys Acta 591: 82-91

Nakazato K, Toyoshima C, Enami I and Inoue Y (1996) Twodimensional crystallization and cryo electron microscopy of Photosystem II. J Mol Biol 257: 225-232 
Nanba O and Satoh K (1987) Isolation of a Photosystem II reaction center consisting of D1 and D2 polypeptides and cytochrome b559. Proc Natl Acad Sci USA 84: 109-112

Nield J, Orlova E, Morris E, Gowen B, van Heel M and Barber J (2000a) 3D map of plant Photosystem II supercomplex obtained by cryoelectron microscopy and single particle analysis. Nat Struct Biol 7: 44-47

Nield J, Funk C and Barber J (2000b) Supermolecular structure of Photosystem two and location of the PsbS protein. Phil Trans R Soc London B 355: 1337-1344

Nield J, Balsera M, Dr Las Rivas J and Barber J (2002) 3D cryo-EM study of the extrinsic domains of the oxygen evolving complex of spinach. Assignment of the PsbO protein. J Biol Chem 277: 15006-15012

Ojakian GK and Satir P (1974) Particle movements in chloroplast membranes: quantitative measurements of membrane fluidity by freeze-fracture technique. Proc Natl Acad Sci USA 21: 2052-2054

Olson JM and Blankenship RE (2004) Thinking about the evolution of photosynthesis. Photosynth Res 80: 373-386 (this issue)

Park R and Sane PV (1971) Distribution of function and structure in chloroplast lamellae. Annu Rev Plant Physiol 22: 395-430

Pecoraro VL, Baldwin MJ, Hsieh W-Y and Law NA (1998) A proposal for water oxidation in Photosystem II. Pure Appl Chem 70: 925-929

Peter GF and Thornber JP (1991) Biochemical composition and organization of higher plant Photosystem II light harvesting pigment-proteins. J Biol Chem 266: 16745-16754

Porter G, Tredwell CJ, Searle GFW and Barber J (1978) Picosecond time resolved energy transfer in Porphyridium cruentum Part I. In the intact alga. Biochim Biophys Acta 501: 232-245

Prokhorenko VI and Holzwarth AR (2000) Primary processes and structure of Photosystem II reaction center: a photon echo study. J Phys Chem 104: 11563-11578

Renger G (2003) Apparatus and mechanism of photosynthetic oxygen evolution: a personal perspective. Photosynth Res 76: 269-288

Rhee KH (1998) Three dimensional structure of Photosystem II reaction center by electron cryo-microscopy. $\mathrm{PhD}$ thesis. University of Frankfurt, Germany

Rhee KH, Morris EP, Zheleva D, Hankamer B, Kühlbrandt W and Barber J (1997) Two dimensional structure of plant Photosystem II at $8 \AA$ resolution. Nature 389: 522-526

Rhee KH, Morris EP, Barber J and Kühlbrandt W (1998) Three dimensional structure of the Photosystem II reaction centre at $8 \AA$ resolution. Nature 396: 283-286

Rubin B and Barber J (1980) The role of membrane surface charge in the control of photosynthetic processes and involvement of electrostatic screening. Biochim Biophys Acta 592: 87-102

Rutherford AW, Govindjee and Inoue Y (1984) Charge accumulation and photochemistry in leaves studied by thermoluminescence and delayed light emission. Proc Natl Acad Sci USA 81: 1107-1111

Sane PV, Goodchild DJ and Park RB (1970) Characterization of chloroplast Photosystems 1 and 2 separated by a non-detergent method. Biochim Biophys Acta 218: 162-178

Satoh K (2003) The identification of the Photosystem II reaction center: a personal story. Photosynth Res 76: 233-240

Schubert W-D, Klukas O, Saenger W, Witt HT, Fromme P and Krauß N (1998) A common ancestor for oxygenic and anoxygenic photosynthetic systems - a comparison based on the structural model of Photosystem I. J Mol Biol 280: 297-314
Seibert M (1995) Reflections on the nature and function of the Photosystem II reaction centre. Aust J Plant Physiol 22: $161-166$

Seibert M and Wasielewski MR (2003) The isolated Photosystem II reaction center: first attempts to directly measure the kinetics of primary charge separation. Photosynth Res 76: 263-268

Seibert M, DeWit M and Staehelin LA (1987) Structural localization of the oxygen evolving apparatus to multimeric (tetrameric) particles on the lumenal surface of freeze-etched photosynthetic membranes. J Cell Biol 105: 2257-2265

Seibert M, Picorel R, Rubin AB and Connolly JS (1988) Spectral, photophysical, and stability properties of isolated Photosystem II reaction center. Plant Physiol 87: 303-306

Siegbahn PEM (2002) Quantum chemical studies of manganese centers in biology. Curr Opin Chem Biol 6: 227-235

Staehelin LA (1976) Reversible particle movements associated with unstacking and restacking of chloroplast membranes. J Cell Biol 71: 136-158

Staehelin LA (2003) Chloroplast structure: from chlorophyll granules to supra-molecular architecture of thylakoid membranes. Photosynth Res 76: 185-196

Staehelin LA, Armond PA and Miller KR (1976) Chloroplast membrane organization at the supramolecular level and its functional implications. Brookhaven Symp Biol 28: 278-315

Strehler B and Arnold W (1951) Light production from green plants. J Gen Physiol 34: 809-820

Svensson B, Etchebest C, Tuffrey P, van Kan P, Smith J, Styring S (1996) A model for the Photosystem II reaction center core including the structure of the primary donor P680. Biochemistry 35: 14486-14502

Telfer A, Bishop SM, Phillips D and Barber J (1994) Isolated photosynthetic reaction center of Photosystem II as a sensitizer for the formation of singlet oxygen: detection and quantum yield determination using a chemical trapping technique. J Biol Chem 269: 13244-13253

Vass I (2003) The history of photosynthetic thermoluminescence. Photosynth Res 76: 303-318

Vass I and Inoue Y (1992) Thermoluminescence in the study of Photosystem II. In: Barber J (ed) Topics in Photosynthesis, Vol 11, pp 259-294. Elsevier, Amsterdam

Vrettos JS, Limburg J and Brudvig GW (2001) Mechanism of photosynthetic water oxidation; combining biophysical studies of PS II with inorganic model chemistry. Biochim Biophys Acta 1503: 229-245

Wakoo N, Yokoi N, Isoyama N, Hiraishi A, Shimada K, Kobayashi M, Kise H, Iwaki M, Itoh S, Takaichi S and Sakurai Y (1996) Discovery of natural photosynthesis using $\mathrm{Zn}$-containing bacteriochlorophyll in an aerobic bacterium Acidiphilium rubrum. Plant Cell Physiol 37: 889-893

Wasielewski M, Johnson DG, Preston C, Govindjee and Seibert M (1989) Determination of the primary charge separation rate in isolated Photosystem II reaction centers with $500 \mathrm{fs}$-time resolution. Proc Natl Acad Sci USA 86: 524-528

Witt HT (2004) Steps on the way to building blocks, topologies, crystals and X-ray structural analysis of Photosystems I and II of water-oxidizing photosynthesis. Photosynth Res 80: 85-107 (this issue)

Wraight CA and Crofts AR (1970) Energy-dependent quenching of chlorophyll $a$ fluorescence in isolated chloroplasts. Eur $\mathbf{J}$ Biochem 17: 319-327

Wraight CA and Crofts AR (1971) Delayed fluorescence and the high energy state of chloroplasts. Eur J Biochem 19: 386-397 
Zhang ZH, Mayes SR, Vass I, Nagy L and Barber J (1993) Characterisation of the psbK locus of Synechocystis sp. PCC 6803 in terms of PS II function. Photosynth Res 38: 369-377

Zheleva D, Sharma J, Panico M, Morris HR and Barber J (1998) Isolation and characterization of monomeric and dimeric CP47RC PS II complexes. J Biol Chem 273: 16122-16127
Zouni A, Jordan R, Schlodder E, Fromme $\mathrm{P}$ and Witt HT (2000) First Photosystem II crystals capable of water oxidation. Biochim Biophys Acta 1457: 103-105

Zouni A, Witt HT, Kern J, Fromme P, Krauß N, Saenger W and Orth P (2001) Crystal structure of Photosystem II form Synechococcus elongatus at $3.8 \AA$ Aresolution. Nature 409: 739-743 